\title{
Le rituel irlandais de consécration des églises au Moyen Âge : le témoignage des sources irlandaises et bretonnes
}

The Irish ritual of the consecration of churches in the Middle Ages: the evidence of the Irish and Breton sources

\section{Dominique Barbet-Massin}

\section{OpenEdition}

Journals

Édition électronique

URL : http://journals.openedition.org/abpo/1997

DOI : 10.4000/abpo. 1997

ISSN : 2108-6443

\section{Éditeur}

Presses universitaires de Rennes

Édition imprimée

Date de publication : 30 mai 2011

Pagination : 7-39

ISBN : 978-2-7535-1691-5

ISSN : 0399-0826

\section{Référence électronique}

Dominique Barbet-Massin, «Le rituel irlandais de consécration des églises au Moyen Âge : le témoignage des sources irlandaises et bretonnes ", Annales de Bretagne et des Pays de l'Ouest [En ligne], 118-2 | 2011, mis en ligne le 30 juin 2011, consulté le 19 avril 2019. URL : http:// journals.openedition.org/abpo/1997; DOI : 10.4000/abpo.1997 


\title{
Le rituel irlandais de consécration des églises au Moyen Âge : le témoignage des sources irlandaises et bretonnes
}

\author{
Dominique BARBET-MASSIN \\ Docteur en histoire médiévale
}

Le rite de consécration des églises du haut Moyen $\widehat{A} g \mathrm{e}^{1}$ est connu en Orient et en Occident par de nombreux textes, sacramentaires ou ordines, écrits dès le VIII ${ }^{\mathrm{e}}$ siècle ${ }^{2}$. Le rite de consécration en Irlande n'est pas aussi connu : on n'en conserve en effet qu'un seul traité, relativement récent (X-XI ${ }^{\mathrm{e}}$ siècle), dans le manuscrit du Leabhar Breac ${ }^{3}$. C'est pourquoi il n'a

1. Cet article est une version remaniée d'un chapitre extrait de ma thèse en histoire médiévale sur l'enluminure insulaire, Le roi en son royaume : symbolique de l'enluminure insulaire (VII ${ }^{e}$-VII ${ }^{e}$ siècles), dir. RouCHE, Michel, soutenue en juin 2010 à l'université de Paris IV-Sorbonne. La discussion s'est enrichie entre temps de nouvelles publications : TREFFORT, Cécile, "Opus litterarum. L'inscription alphabétique et le rite de consécration de l'église (IX ${ }^{\mathrm{e}}-\mathrm{XII}{ }^{\mathrm{e}}$ siècle) ", Cahiers de civilisation médiévale 53 (2010), p. 153-180, et du compte-rendu qui en est fait par StiRnEmann, Patricia, "L'inscription alphabétique : de la consécration de l'église à l'apprentissage de la lecture et autres usages ", Bulletin monumental, 169-1 (2011), p. 73-76; Ó CARRAGÁIN, Tomás, Churches in Early medieval Ireland : architecture, ritual and memory, Newhaven, London, Yale University Pr., 2010.

2. Sur le rite de la consécration d'église, voir Duchesne, Louis, Origines du culte chrétien : étude sur la liturgie latine avant Charlemagne, Paris, De Boccard, (5 éd.), ch. 12, p. 420 439; Puniet, Pierre de, " Dédicace des églises ", Dictionnaire d'Archéologie Chrétienne et de Liturgie (DACL), 1920, T. 4, col. 374-405; Jounel, Pierre, " Dédicace des églises et des autels ", Dictionnaire encyclopédique de la liturgie, éd. SARTORI, Domenico, TrIACCA, Achille M., Turnhout, Brepols, 1992, vol. I, p. 261-271; REPSHER, Brian, The rite of church dedication in the early medieval era, Lewiston (New York), E. Mellen Pr., 1998; PALAzzo, Eric, Liturgie et société au Moyen Âge, Paris, Aubier, 2000, p. 71-77; IoGNA-PRAT, Dominique, La Maison Dieu : une histoire monumentale de l'Eglise au Moyen Âge (v. 800-v. 1200), Paris, Seuil, 2006, p. 45-47, 172-176, 260-276.

3. Le Leabhar Breac ou "Livre tacheté " (Royal Irish Academy, MS.23 P 16) est un manuscrit au contenu principalement religieux, compilé vers 1411 ou un peu avant par un des membres de la famille des MacEgans de Muscrige-Tíre, dans le nord du Tipperary. Voir KENNEY, James F., The sources for the early history of Ireland : Ecclesiastical. An introduction and guide, Columbia University Press, 1929. Seconde Réimpr. Octagon Books, 1979, p. 25. Il appartient à la Royal Irish Academy qui en a publié un fac-similé en 1876. Ses pages sont maintenant numérisées et se trouvent sur le site internet ISOS «Irish script 
jusqu'ici été que peu étudié, même s'il a été édité à deux reprises ${ }^{4}$. Il est cependant possible, en analysant le détail de ce texte et en le comparant avec les textes des sacramentaires et ordines continentaux, de se faire une idée plus précise de l'origine et de l'ancienneté du rite de dédicace en Irlande. La découverte d'un schéma de consécration d'une église, contenu dans un manuscrit d'Angers (fin IX ${ }^{\mathrm{e}}$ siècle) ${ }^{5}$, et fort proche du texte irlandais, permet de préciser les détails de ce rite et d'en faire ressortir les éléments originaux propres à l'Irlande. Certains de ces éléments, à leur tour, se retrouvent dans des textes hagiographiques anciens qui permettent de déterminer leur origine et leur diffusion.

\section{L'ordo irlandais et les autres ordines du Moyen Âge}

\section{Le traité irlandais du Leabhar Breac}

Le traité irlandais sur la consécration des églises occupe un peu plus d'une page du manuscrit du Leabhar Breac, de la page 277, $1^{\text {re }}$ colonne, ligne 26 à la page $278,1^{\text {re }}$ colonne, ligne 55 , soit un texte d'environ 165 lignes, dont certaines sont peu lisibles ou ont disparu, le parchemin étant très abîmé en haut des pages à cet endroit du livre.

Le texte, dans une courte introduction (§ 1-6), présente les cinq parties principales du traité : le sol, l'autel et son ameublement, la consécration à l'extérieur avec les douze psaumes, l'aspersion d'eau à l'intérieur, l'aspersion d'eau à l'extérieur. Le texte s'arrête après quelques lignes de la quatrième partie, et ne comprend pas du tout la cinquième, sans explication; peut-être manquait-elle dans le manuscrit recopié ${ }^{6}$. Puis les parties annoncées sont décrites dans le détail. La première partie, sur le sol (§ 9-15),

on screen ", à l'adresse www.isos.dcu.ie. Le manuscrit est un grand folio de 280 pages, rédigé sur deux colonnes d'une écriture serrée, certaines pages ne comportant pas moins de quatre-vingt lignes par colonne. La plupart des textes qu'il contient ont été publiés. Son contenu est répertorié dans The passions and the homilies from Leabhar Breac : text, translation, and glossary, éd. ATKInSON, Robert, Dublin, Hodges, Figgis, " Todd Lecture series II ", 1887, p. 36-40. The Irish Nennius from L. na Huidre and Homilies and legends from L. Brecc, éd. Hogan, Edmund, Dublin, Hodges, Figgis, " Todd Lecture series VI ", 1895, donne en outre dans sa préface une liste des éditions arrêtée à la date de 1895, p. VI-VII. Voir aussi les notices de KENNEY, James F., op. cit., p. 739-740, § 616-617.

4. KENNEY, James F., The sources for the early history of Ireland : I. Ecclesiastical, an introduction and guide, New York, Columbia University Pr., 1920 (2e éd. Octagon Printing, 1979), p. 688, § 551. Le traité a été édité et traduit par OldEN, Thos., " On an early Irish tract in the Leabhar Breac describing the mode of consecrating a church ", Transactions of the St Paul's ecclesiastical society IV (1897), p. 98-104 et 177-180. Autre éd. et trad. par STOKES, Whitley, " The Lebar Brecc Tractate on the consecration of a church ", Miscellanea linguistica in onore di Graziado Ascoli, Turin, 1901 (repr. Slatkine, 1973), p. 363-387, avec une division par $\S$, de 1 à 40, reprise ici.

5. Angers, Bibliothèque municipale, ms 477 (461), $\mathrm{f}^{\circ} 9 \mathrm{r}^{\circ}$. Reproduction et édition en annexe.

6. "On an early Irish tract in the Leabhar Breac describing the mode of consecrating a church ", éd. Olden, Thos., Transactions of the St Paul's ecclesiastical society IV (1897), p. 104 , note 7 . 
comprend l'introit, l'entrée (§ 9), avec le détail des psaumes et des prières chantés de l'entrée de l'oratoire à la poutre du seuil ${ }^{7}$, puis à l'intérieur, une fois le seuil franchi ${ }^{8}$; la consécration de l'eau et du sel $(\S 10)$, le sel divisé en trois parts étant mélangé à l'eau, l'évêque chantant une prière tirée du pontifical, puis l'ensemble mis sous l'autel; psaumes et prières contenus dans le livre de l'évêque, pour chasser les démons (§ 11); la même chose pour maudire les démons $(\S 12)$; prières de consécration du sol, chantées du livre de l'évêque ( $(13)$; inscription de l'alphabet sur le sol, deux fois, du sud-est au nord-ouest pour le premier, puis du nord-est au sud-ouest, de façon à ce que les deux $\mathrm{O}$ des alphabets se croisent au milieu (§ 14). Une dernière opération n'est plus lisible (§ 15).

La deuxième partie concerne la consécration de l'autel et de son ameublement ( $(16-22)$. Tout d'abord, l'hostie, le vin et l'eau sont mélangés et consacrés (§ 17), selon le rite indiqué dans le livre de l'évêque; puis la table d'autel est consacrée par l'évêque (§ 18), qui grave avec son couteau quatre croix aux quatre coins de l'autel, plus trois autres croix au milieu, c'est-àdire une au centre, une deuxième au milieu du bord à l'est, la troisième au milieu du bord à l'ouest. Après cela, l'évêque lave l'autel avec le mélange d'eau, de vin et d'hostie, il verse ce qui reste au pied de l'autel, essuie la table avec un tissu de lin, allume de l'encens dessus tout en chantant le psaume 141, $2(140,2)^{9}$ et enfin oint les sept croix de l'autel avec l'huile consacrée; après cela, consécration de la nappe d'autel (§ 19), qui est installée; puis de l'impetóir ${ }^{10}$, la patène $(\S 20)$, petit plat ou tissu qui reçoit le corps du Christ ; consécration du calice $(\$ 21)$; puis consécration générale de l'autel et de son ameublement (§ 22).

La troisième partie concerne la consécration de l'église (§ 23-35), faite à l'extérieur par l'évêque et deux prêtres, à l'intérieur par trois prêtres. Le traité fait une description précise de cette étape de la cérémonie et en décrit même

7. Crand mbith, "poutre du seuil ". La traduction est celle de Whitley Stokes. Thos. Olden ne le traduit pas mais rapporte son opinion et celle de Whitley Stokes, p. 180. Il le voit au départ comme un ambitus autour de l'autel, mais Whitley Stokes se réfère au Glossaire de O'Davoren, Three Irish glossaries, éd. STOKEs Whitley, London, Williams and Norgate, 1862, p. 57, où bith, génitif de bi, est expliqué comme étant un seuil (tairsich). Thos. Olden explique alors le seuil, limen en latin, comme un sanctuaire, d'après un usage ecclésiastique ancien, et propose une traduction de crand mbith par 'barrière en bois du sanctuaire'. Le texte irlandais peut être interprété des deux façons : inni chanar iarum $i$ ndorus in daurthige conice in crand mbith co canar Pater Noster.

8. De l'entrée à la poutre du seuil : ps. $66,13(65,13)$ jusqu'à Laudabo te et un Pater Noster; à l'intérieur : ps. 76, $3(75,3)$ et une antienne tirée de Mt. 21, 13.

9. Pour les psaumes, la première numérotation donnée est celle du psautier actuel; entre parenthèses, la numérotation est celle du psautier de la Vulgate corrigé par Jérôme, dans la version dite "psautier gallican".

10. Thos. Olden, p. 180, suivi par Whitley Stokes, pense qu'il s'agit ici de l'antimension byzantin, planche ou tissu qui remplaçait la table d'autel (voir PÉTRIDĖS, S., " Antimension ", DACL I, 2, 1907, col. 2319-2326). Mais il s'agit de la patène. Voir DIL (Contributions to a Dictionary of the Irish Language, based mainly on Old and Middle Irish Materials), Dublin, Royal Irish Academy, 1913-1976, I, col. 163; GwynN, Edward J., " Some Irish words ", Hermathena 21, ${ }^{\circ} 46$ (1931), §9, p. 8-12. 
deux usages différents, selon les auteurs traitant de ce sujet. L'évêque fait le tour de l'église à l'extérieur, avec deux prêtres, pendant que trois autres prêtres font de même à l'intérieur. Il part soit de l'est ( $1^{\text {re }}$ version, $§ 27-32$ ), soit de l'ouest ( $2^{\mathrm{e}}$ version, $\left.\S 33-35\right)$. Le tour se termine à la porte de l'église, à l'ouest. S'il choisit la première solution, le tour (est-sud, sud-ouest, ouestnord, nord-ouest) l'oblige à aller à l'est sans chanter, ce qui semble aller à l'encontre de la cérémonie ( $(35)$, selon les défenseurs du tour par l'ouest. Les justifications données pour le début du tour de l'église à l'est sont moins pratiques (§ 32) : l'est est la partie la plus noble, parce que c'est là que se trouve le Paradis d'Adam, là que commence l'adoration de la croix dans chaque église, la croix ayant le dos à l'ouest; c'est aussi à l'est que se lève le soleil, qui est une appellation du Christ, lequel viendra de l'est au Jugement dernier; enfin, c'est de l'est qu'on écrit l'alphabet dans l'église.

Quel que soit le point de départ, l'évêque grave une croix sur la colonne de l'est. Le texte ne dit pas s'il grave une croix à chaque arrêt. En faisant le tour de l'église, l'évêque chante douze psaumes (§ 27-30), les psaumes graduels, 120 à 131 (119 à 130), trois par point cardinal, avec des antiennes, l'une tirée du troisième psaume chanté, puis le Gloria et Sicut erat in principio nunc et semper. Les mêmes psaumes sont chantés à l'intérieur, suivant le même circuit. À partir du dernier angle, l'évêque entonne le psaume 24 (23) (§ 31), sur l'entrée solennelle de Yahvé dans le sanctuaire, de façon à ce que, arrivé à la porte de l'église, il chante la deuxième partie du psaume et demande qu'on lui ouvre la porte pour laisser entrer le Roi de gloire, pendant qu'un des prêtres restés à l'intérieur demande qui est le Roi de gloire. L'évêque entre en chantant le même introit qu'à la première entrée (§ 31).

La quatrième partie du traité, et la dernière conservée par le manuscrit quoique fortement amputée, concerne l'aspersion d'eau bénite sur les murs intérieurs (§ 36-40). Le diacre prend l'eau et le sel sous l'autel, l'évêque à l'angle sud-est de l'église grave une croix sur le pinacle et l'asperge avec l'eau consacrée (§ 37), pendant que trois prêtres aspergent les murs, la cuve baptismale et le toit avec une branche d'hysope ${ }^{11}$ (§ 38), en chantant une antienne tirée du psaume 51 (50) et le psaume 6 (5), ainsi que le Gloria ${ }^{12}$ et Sicut erat in principio nunc et semper (§ 39). La même chose se répète à

11. Plante aromatique de la famille des labiacées; fréquemment citée dans la Bible, symbole de la petitesse par opposition à la grandeur du cèdre, l'hysope est utilisée dans les rituels de consécration des églises pour asperger l'église.

12. Le Gloria in excelsis deo, appelé grande doxologie, est une prière de glorification, qui reprend le verset de Luc 2, 14, lorsque les anges annoncent la Nativité aux bergers. Elle se trouve dans l'Antiphonaire de Bangor, composé entre 680 et 690. C'est là une de ses plus anciennes apparitions latines. JEFFERY, Peter, "Eastern and Western elements in the Irish monastic prayer of the hours ", The Divine office in the Latin Middle Ages : methodology and source studies, regional developments, hagiography, written in honour of Professor Ruth Steiner, éd. FASSLER, Margot E., BALTZER, Rebecca A., Oxford, University Pr., 2000, p. 99-143, voir p. 138, note 47. Le Gloria se trouve aussi dans le Missel de Stowe et les textes de Irish liber hymnorum. Voir StEvEnson, Jane, "Irish hymns, Venantius Fortunatus and Poitiers ", Aquitaine and Ireland in the Middle Ages, éd. PICARD, Jean-Michel, Dublin, Four Court Pr., 1995, p. 87. 
l'angle sud-ouest de l'église, puis au nord-ouest (§ 40)... Le texte s'arrête là, mais il est vraisemblable que non seulement tous les angles intérieurs sont ainsi gravés d'une croix et aspergés d'eau bénite, mais aussi que l'opération se répète de la même façon à l'extérieur, décrite dans la cinquième partie manquante.

L'église est ainsi marquée de croix d'abord gravées puis bénites aux différents points cardinaux, la première fois à l'extérieur au moins à l'est, si ce n'est aux autres points ${ }^{13}$, le parcours s'arrêtant aussi au sud, au nord et à l'ouest; une seconde fois à l'intérieur et à l'extérieur aux points collatéraux. L'alphabet dessiné sur le sol dessine une croix de saint André qui part des points collatéraux, explicitement désignés. Les angles de l'autel sont aussi gravés de croix, ainsi que le milieu où trois croix soulignent l'axe est-ouest. L'espace rectangulaire ${ }^{14}$ est ainsi orienté, de manière insistante, plusieurs fois, et marqué d'une croix. L'église étant orientée est-ouest, les points collatéraux situés aux angles sont aussi mentionnés.

\section{Datation et éléments d'origine du traité}

Le traité se trouvant dans un manuscrit du $\mathrm{Xv}^{\mathrm{e}}$ siècle, il est intéressant de voir dans quelle mesure il est original et jusqu'à quand il est possible de reculer la date de sa rédaction ou des éléments qu'il contient. Le premier éditeur de ce texte le fait remonter à une date antérieure à 1186 , année où se tint un synode irlandais à Dublin, dont un des canons interdit la célébration de la messe sur un autel en bois, comme c'était encore l'usage en Irlande, et ordonne qu'une pierre ou mensa d'une taille suffisante pour y tracer cinq croix et recevoir le pied d'un calice soit insérée dans l'autel. Or, le traité ne mentionne aucune pierre insérée dans l'autel et le nombre de croix gravées est de sept et non cinq. Qui plus est, le texte spécifie que l'évêque grave lui-même avec son couteau les croix sur l'autel, qui devait donc être en bois ${ }^{15}$.

Contrairement à l'usage établi dans l'Église depuis au moins le début $\mathrm{du} \mathrm{VI}{ }^{\mathrm{e}}$ siècle (concile d'Épaone (Bourgogne) de 517 , canon 26$)^{16}$, les Irlandais ont en effet conservé très tard l'utilisation du bois pour les autels. Cependant, les autels en pierre n'étaient pas inconnus, l'autel étant qualifié

13. C'est cependant peu vraisemblable, le texte n'en faisant pas mention, alors qu'il note pour le reste de manière très explicite l'ensemble des points cardinaux.

14. L'église en Irlande est un simple rectangle. Ó CARRAGÁIN Tomás, Churches in Early medieval Ireland : architecture, ritual and memory, Newhaven, London, Yale University Pr., 2010, p. 33-35 et p. 230. Voir aussi ma thèse, op. cit., Iv ${ }^{\mathrm{e}}$ partie, chap. 3, « Du cercle au rectangle".

15. "On an early Irish tract in the Leabhar Breac describing the mode of consecrating a church ", éd. OLDEN, Thos., Transactions of the St Paul's ecclesiastical society IV, 1897, p. 98. Voir aussi Braun, Joseph, Der christliche Altar, München, G. Koch \& co., 1924, vol. I, p. 105-106.

16. Les Canons des conciles mérovingiens (Ve-VII siècles), éd. GAUDEMET, Jean, BASDEVANT, Brigitte, Paris, Le Cerf, « Sources chrétiennes, n 353-354 », 1989, 2 vol., vol. 1, p. 112, c. 26. 
de " pierre d'adoration " dans les Lois irlandaises ${ }^{17}$, mais ils semblent avoir été plus rares : Tirechán mentionne en effet de tels autels, mais dans ce cas-là, il en précise la matière, altare lapideum ${ }^{18}$. Il est plus probable que les tables d'autels étaient en bois, recouvertes de métal précieux. L'évêque Assicus, le forgeron de Patrick, fabrique en effet des plaques d'autel en même temps que des reliquaires et des patènes ${ }^{19}$. L'autel de saint Cuthbert, qu'on a retrouvé dans sa tombe et qu'on date du VII siècle, était composé d'une planche de chêne, gravée de cinq croix, une au centre et quatre aux quatre coins, et d'une inscription en l'honneur de saint Pierre. Il fut recouvert, sans doute au milieu du VIII ${ }^{\mathrm{e}}$ siècle, de deux plaques d'argent décorées ${ }^{20}$. Les églises étaient pour la plupart construites en bois, " selon l'usage $\operatorname{scot}^{21}$ ", aux linteaux de portes et aux murs sculptées d'entrelacs pour les plus riches ${ }^{22}$, et au toit terminé par des pinacles. On en trouve sans doute une illustration dans le Livre de Kells (Tentation du Christ, $\left.\mathrm{f}^{\circ} 202 \mathrm{v}^{\circ}\right)^{23}$. Les églises devaient avoir une ressemblance avec les églises scandinaves encore conservées de nos jours ${ }^{24}$.

Le traité de consécration des églises du Leabhar Breac reste cependant difficile à dater. Le texte est une traduction irlandaise d'un ordo en latin, dont il reproduit des fragments de phrases. Le second éditeur du texte, Whitley Stokes, le date du XI ${ }^{\mathrm{e}}$ siècle, d'après l'état de la langue, où l'on distingue le passage du vieil-irlandais au début du moyen-irlandais ${ }^{25}$. Le début du moyen-irlandais étant aujourd'hui daté du début du $\mathrm{X}^{\mathrm{e}}$ siècle $^{26}$,

17. Ancient laws and institutes of Ireland $(A L)$, éd. O'DONOvAn, John, O'CuRRY, Eugene, et al., Dublin, A. Thom, Hodges, Smith and co., 1865-1901, 6 vol., T. V, p. 472-473.

18. The Patrician texts in the Book of Armagh, éd. BIELER, Ludwig, Dublin, Dublin Institute of Advanced Studies (DIAS), 1979, § 16/5, p. 136 ; § 19/5, p. 138.

19. Ibid., $\S 22 / 1$, p. 140 .

20. RADFORD C. A. R., "The portable altar of saint Cuthbert ", The relics of saint Cuthbert, éd. BAtTiscombe, C. F., Oxford, University Pr., 1956, p. 327-335. CoAtsworth, Elizabeth, "The pastoral cross and portable altar from the tomb of St Cuthbert", St Cuthbert, his cult and his community to AD 1200, éd. Bonner, Gerald, Rollason, David, STANCLIFFe, Clare, Woodbridge (Suffolk), Boydell Pr., 1989, p. 287-301.

21. Gougaud Louis, "Liturgies celtiques ", DACL, col. 2969-3032 (col. 2993). BÈDE LE VÉNÉRABLE, Histoire ecclésiastique du peuple anglais, éd. LAPIDGE, Michael, trad. MonAT, Pierre, RoBIN, Philippe, intr. et notes CRÉPIN, André, Paris, Le Cerf, "Sources Chrétiennes n 490 ", 2005, T. 2, Livre III, 4, p. 32-33 et 25, p. 142-143 et 4. BERnARD DE ClaIRVAUX, "Vie de saint Malachie ", Éloge de la nouvelle chevalerie. Vie de saint Malachie. Epitaphe, hymnes, lettres, éd. EMERY Pierre-Yves, Paris, Le Cerf, "Sources Chrétiennes n 367 », 1990, VI, 14, p. 220-221.

22. "Betha Máedóc Ferna (I) = Life of Maedoc of Ferns (I) ", Bethada náem nErenn, Lives of Irish Saints, éd. Plummer, Charles, Oxford, Clarendon Pr., 1922, 2 vol., vol. 1, p. 188, trad. vol. 2, p. 182.

23. Harbison, Peter, L’Art médiéval en Irlande, La-Pierre-Qui-Vire Zodiaque, 1998, p. 123.

24. AnKer, Peter, Andersson, Aron, L'Art scandinave, La-Pierre-Qui-Vire, Zodiaque, " La nuit des temps ", 1969, 2 vol., vol. I, pl. 100-160.

25. "The Lebar Brecc Tractate on the consecration of a church ", éd. STOKEs, Whitley, Miscellanea linguistica in onore di Graziado Ascoli, Turin, 1901 (repr. Slatkine, 1973), p. 363.

26. ThuRNEYSEN, Rudolf, A grammar of Old-Irish : revised and enlarged edition, with supplement, trad. de l'all. BinchY, Daniel A., BERGin, Osborn, Dublin, Institute for Advanced Studies, School of Celtic Studies, 1993, p. 1. 
sans doute peut-on situer la composition du traité entre le $\mathrm{X}^{\mathrm{e}}$ et le $\mathrm{XI}^{\mathrm{e}}$ siècle. Celui-ci indique souvent la récitation de certaines prières " comme il est dit dans le livre de l'évêque " : ut dicitur in libro episcopi (§ 21) ou amal... isin libar escuip (§ 9-13, 17-18, 22, 39) et parle d'ordo consecrationum ou consecrationis $(\S 2,16)$. L'ordo est donc recopié d'après un pontifical, livre qui apparaît tardivement, vers les $\mathrm{IX}^{\mathrm{e}}-\mathrm{X}^{\mathrm{e}}$ siècles ${ }^{27}$. Le texte, toutefois, semble comporter des éléments qui remontent à des époques antérieures.

Tout d'abord, le traité a de nombreux points communs avec les sacramentaires gallicans du $\mathrm{VIII}^{\mathrm{e}}$ siècle, dont certains conservent des textes remontant au $\mathrm{VII}^{\mathrm{e}}$ siècle ${ }^{28}$, et avec les plus anciens ordines conservés, qui datent du VIII ${ }^{\mathrm{e}}$ siècle $^{29}$. Il est proche en particulier de l'ordo 41 , gallican, avec lequel il partage beaucoup de rubriques. Les éléments gallicans et romains sont repris dans les deux ordines de la dédicace des églises du Pontifical Romano-Germanique du $\mathrm{x}^{\mathrm{e}}$ siècle, dont la composition remonte au milieu du IX ${ }^{\mathrm{e}}$ siècle $^{30}$. Le traité irlandais a aussi des traits communs avec le rite ambrosien, retrouvé sous deux formes différentes, dans un pontifical du $\mathrm{IX}^{\mathrm{e}}$ siècle $^{31}$, qui est d'ailleurs pour l'essentiel identique dans les termes à

27. VoGEL, Cyrille, Introduction aux sources de l'histoire du culte chrétien au Moyen Âge, Spoleto, Centro Italiano di Studi sull'Alto Medioevo, 1980 (rééd.), p. 182-187.

28. Liber sacramentorum romanae ecclesiae ordinis anni circuiti (Cod. Vat. Reg. Lat. 316/ Paris Bibl. Nat. 7193, 41/56. Sacramentarium Gelasianum), éd. MoHLBERG, Leo Cunibert, Rome, Herder, "Rerum Ecclesiasticarum Documenta. Series Maior. Fontes, IV ", 1960, p. 107-110. Missale Francorum (Cod. Vat. Reg. lat. 257), éd. MoHLBERG, Leo Cunibert, Rome, Herder, « Rerum Ecclesiasticarum documenta. Series Maior. Fontes II » 1957, p. 17-19. Liber sacramentorum Engolimensis : le sacramentaire gélasien d'Angoulême, manuscrit BN lat. 816, éd. SAINT-Roch, Patrick, Turnhout, Brepols, " Corpus Christianorum Series Latinae (CCSL) 159C ", 1987, p. 302-312. Voir Duchesne, Louis, Origines du culte chrétien : étude sur la liturgie latine avant Charlemagne, Paris, De Boccard, 1925 (5e éd.), p. 429-430. HeN, Yitzhak, Culture and religion in Merovigian Gaul AD 481-751, Leiden, Brill, 1995, ch. 2, en particulier p. 52- 53.

29. " Ordo XLI " et " Ordo XLII ", Les Ordines Romani du haut Moyen Âge, éd. ANDRIEu, Michel, Louvain, Spicilegium Sacrum Lovaniense, "Spicilegium Sacrum Lovaniense. Études et documents, fasc. 28 ", 1956, T. IV, p. 309-402. L'ordo romanus 42 décrit le rite de la consécration à Rome vers 700-750, l'ordo romanus 41, celui de l'usage gallican vers 750-775.

30. Le pontifical romano-germanique du $x^{e}$ siècle, éd. Vogel, Cyrille, ELzE, Reinhard, Rome, Vatican, "Studi e Testi, 226 ", 1963. Ces ordines sont l'ordo 33, "Ordo romanus ad dedicandam ecclesiam " p. 82-89, qui est un mélange de l'ordo 41 et de l'ordo 42; et l'ordo 40, "Ordo ad benedicandam ecclesiam", p. 124-173, qui reprend l'ensemble de l'ordo 41 en l'ampllifiant. Trad. REPSHER, Brian, The rite of church dedication in the early medieval era, Lewiston (New York), E. Mellen Pr., 1998, p. 139-169. L'ordo 40 est suivi d'un commentaire carolingien sur la cérémonie "Quid significent duodecim candelae?", éd. Le pontifical romano-germanique du $X^{e}$ siècle, éd. VoGEL, Cyrille, Elze, Reinhard..., p. 90-121, trad. REPSHER, Brian, The rite of church dedication in the early medieval era, Lewiston (New York), E. Mellen Pr., 1998, p. 171-193.

31. "Pontificale saec. ix Mediolanensis Ecclesiae ", éd. Magistretti, Marco, Monumenta Veteris Liturgiae Ambrosianae, Liechtenstein, Kraus Reprint, 1971 (1 ${ }^{\text {ère }}$ éd. 1897), T. I, p. 1-26. Voir aussi Jenner, H., " Ambrosian liturgy and rite ", The Catholic encyclopedia, New York, R. Appleton, 1907. Le rituel du IXe siècle comprend : entrée solennelle, écriture de l'alphabet sur le sol avec la crosse de l'évêque (ABCturium et cambutta), mélange 
l'ordo $41^{32}$, et dans un manuscrit de Lucques du XI ${ }^{\mathrm{e}}$ siècle ${ }^{33}$. Enfin, il reprend certains éléments du rite byzantin, conservé dans sa forme dans un manuscrit du VIII ${ }^{\mathrm{e}}$ siècle $^{34}$.

On retrouve ainsi en particulier la consécration de l'autel et de ses ornements (linge, patène, calice, ensemble des objets liturgiques), énumérés dans le même ordre dans le Sacramentaire gélasien ancien du VIII ${ }^{\mathrm{e}}$ siècle, et auparavant dans le Missale Francorum. C'est l'unique partie de la cérémonie de consécration des églises qui est donnée dans ces sacramentaires décrivant le rite gallican, c'est aussi la plus ancienne.

L'entrée de l'évêque, qui demande qu'on lui ouvre la porte par le chant du psaume 24 (23), se trouve dans l'ordo 41, et dans le rite ambrosien, au début de la cérémonie ${ }^{35}$. Ce rite est également attesté de façon ancienne,

eau, sel, vin et cendres, aspersion et onction de l'église et de l'autel, bénédiction des ustensiles, déposition des reliques. Différences avec l'ordo de Lucques : principalement, avant l'entrée, circumambulation et aspersion, signe de croix sur la porte, alphabet sur les murs et onction de 3 croix sur chaque mur avec le chrisme; après l'entrée, pas de déposition de reliques.

32. L'ordo 41 est composé, dans l'édition de Michel Andrieu, de 31 §, et d'un appendice tiré d'un des manuscrits contenant l'ordo, le Cod. 102 de Zurich (Z), des $\mathrm{IX}^{\mathrm{e}}-\mathrm{X}^{\mathrm{e}}$ siècles, reprenant des leçons de la messe de dédicace en $9 \S$. Le rite ambrosien du Ix ${ }^{\mathrm{e}}$ siècle est édité en 64 § par Marco Magistretti. Les 31 § de l'ordo 41 sont presque mot pour mot ceux du pontifical ambrosien, $\S 1$ à 5, 9 à 17, 19 à 26, 50, 55, 57-58. Les $§ 60,61$ et 62 correspondent aux $\S 1,6$ et 7 de la messe de dédicace contenue dans le Cod. 102 de Zurich. Les $\S$ du manuscrit ambrosien absents dans l'ordo 41 correspondent soit à une simplification de la cérémonie, soit à une deuxième version des prières. Pour le texte commun, l'abréviation des prières est la principale différence entre les deux textes. On retrouve cependant le texte complet de beaucoup de ces prières dans le Cod. 102 de Zurich.

33. "Ordo Ambrosianus ad consecrandam ecclesiam et altaria ", éd. MERCATI, Giovanni, Antiche reliquie liturgiche ambrosiane e romane, Rome, Vatican, "Studi e testi, 7 ", 1902, p. 5-32. PuniET, Pierre de, "La consécration des églises", Revue des questions historiques, Nouv. Série T. 33 (1905), p. 596-603. Giovanni Mercati ne date pas l'ordo retrouvé dans le manuscrit du XI ${ }^{\mathrm{e}}$ siècle, mais Pierre de Puniet pense que certains éléments en sont très anciens. Voir aussi PuniET, Pierre de, "Dédicace des églises ", DACL, 1920, T. 4, col. 396, §5. DuCHESNE, Louis, Origines du culte chrétien : étude sur la liturgie latine avant Charlemagne, Paris, De Boccard, 1925 ( $5^{\mathrm{e}}$ éd.), p. 429, note 2, pense cependant que ce texte ne serait qu'une forme remaniée du pontifical milanais du IX siècle. GRos, Miquel, « L'ordo pour la dédicace des églises dans le sacramentaire de Nonantola ", Revue bénédictine 79 (1969), p. 368-374, rapproche toutefois certaines parties de l'ordo ambrosien de Lucques de l'ordo de Nonantola, qu'il date entre le milieu du VI ${ }^{\mathrm{e}}$ siècle et la fin du VIII ${ }^{\mathrm{e}}$ et pense originaire de Ravenne. Les pièces communes sont principalement la signation de la croix sur les portes, la prière devant la porte, celle au milieu de l'église. Miquel Gros rapproche aussi ces deux ordines de l'ordo romain 42.

34. L'Eucologio Barberini gr. 336, éd. PAREnTI, Stefano, VelKovsKa, Elena, Rome, CLV-Ed. Liturgiche, 2000, p. 155-164, trad. p. 326-333, § 149-156. FYRILLAS, André K., " Le rite byzantin de la consécration et dédicace d'une église ", La Maison-Dieu 70 (1962), p. 131-134, suivi de " Ordo de la dédicace au rite byzantin ancien (Codex Barberini) ", trad fr. La MaisonDieu 70 (1962), p. 135-140.

35. " Ordo XLI ", Les Ordines Romani du haut Moyen Âge, éd. ANDRIEU, Michel, Louvain, Spicilegium Sacrum Lovaniense, "Spicilegium Sacrum Lovaniense. Études et documents, fasc. 28 ", 1956, T. IV, p. 319. 
dès le vi ${ }^{\mathrm{e}}$ siècle, à Constantinople ${ }^{36}$, et on le retrouve dans l'Euchologe Barberini, mais au début de la cérémonie de consécration des reliques. Dans le traité irlandais, le psaume 24 (23) est récité après le tour de consécration de l'église, à l'extérieur. La cérémonie d'entrée suivie des aspersions de l'église, et accompagnée des mêmes prières que dans les rites gallican et romain [psaume 51 (50)], apparaît, de façon un peu artificielle dans le texte irlandais, séparée de la consécration du sol et de l'autel, qui sont signalées comme étant les plus importantes ${ }^{37}$, par la troisième partie sur la consécration de l'église. Il est possible que l'ensemble de la consécration de l'église, comprenant le tour avec le chant des douze psaumes, et ceux avec les aspersions, ait été déplacé en fin de texte alors que leur place originale était au début dans le "livre de l'évêque " recopié par le traité ${ }^{38}$, peut-être pour ne pas interférer avec l'unité de la première partie, la consécration du sol. La cérémonie comprendrait alors un premier tour de l'église avec les psaumes, l'entrée une fois la porte ouverte, la préparation de l'eau bénite, l'aspersion de l'église à l'intérieur et à l'extérieur, puis l'inscription de l'alphabet, et enfin la consécration de l'autel. On aurait alors un rite proche du rite ambrosien décrit dans le manuscrit de Lucques ou de l'ordo 41, également proche des ordines du Pontifical romano-germanique, hormis la consécration des reliques. Cette hypothèse permettrait d'expliquer l'existence de deux rites de consécration de l'eau, à deux moments différents pour deux usages différents, et de comprendre, en particulier, pourquoi l'eau est consacrée une première fois, puis cachée sous l'autel en attendant de servir pour les aspersions des murs. Il se peut aussi, le traité faisant état de plusieurs traditions différentes, qu'on ait là le résultat de la juxtaposition de plusieurs rites différents, le premier, indiqué comme le plus important pour la consécration de l'église, comprenant la consécration du sol et de l'autel, proche de ceux qu'on retrouve dans les sacramentaires gallicans, datés du VII e siècle, et qui ne comprennent que la consécration de l'autel. Le tour de l'église aurait été rajouté plus tard, et se serait interféré entre la consécration de l'autel et l'aspersion des murs, qui se suivent sans interruption dans l'ordo 41 et l'ordo 40 du Pontifical Romano-Germanique. Ce tour de l'église qui constitue la troisième partie, appelée dans le traité " consécration de l'église ", est d'ailleurs la seule pour laquelle il n'est pas fait mention des instructions du livre de l'évêque.

36. Ibidem, T. IV, p. 316-318.

37. "The Lebar Brecc Tractate on the consecration of a church ", éd. STOKES, Whitley, Miscellanea linguistica in onore di Graziado Ascoli, Turin, 1901 (repr. Slatkine, 1973), p. 374$375, \S 23$.

38. "Ordo Ambrosianus ad consecrandam ecclesiam et altaria ", éd. MERCATI, Giovanni, Antiche reliquie liturgiche ambrosiane e romane, Rome, Vatican, "Studi e testi, 7 ", 1902, p. 30-31 ('Appendice. Il trattato irlandese circa la consecrazione della chiese'). 


\section{Inscription de l'alphabet}

La cérémonie de l'inscription de l'alphabet sur le sol est également décrite dans l'ordo 41, et c'est là son attestation la plus ancienne ${ }^{39}$. Comme le traité irlandais, l'ordo 41 ne précise pas la langue de ces deux alphabets, latins ou bien latin et grec. L'inscription de l'alphabet est accompagnée de la récitation du psaume 119 (118) dans le manuscrit de Lucques, où il est inscrit sur la cendre répandue en forme de croix ${ }^{40}$. Il a par ailleurs été démontré que l'origine de l'inscription de l'alphabet est sans doute irlandaise, par l'emploi du mot cambutta, utilisé pour la crosse de l'évêque au lieu de baculus, et du mot abcturium pour l'alphabet, mots qu'on retrouve dans presque tous les ordines de consécration des églises, en dehors de celui de Lucques qui utilise les mots latins baculus, uirga pastoralis et alfabetum $^{41}$. Il n'est cependant pas question de la crosse de l'évêque dans le traité irlandais, ni pour inscrire l'alphabet, ni pour taper à la porte.

Le rite ambrosien du manuscrit de Lucques prescrit également, avant l'entrée dans l'église, l'inscription de l'alphabet sur les murs à l'extérieur, et douze onctions en forme de croix, trois par mur, en allumant trois chandelles. On retrouve l'inscription de l'alphabet sur les murs dans des pontificaux espagnols qui sont également du XI ${ }^{\mathrm{e}}$-début du XII ${ }^{\mathrm{e}}$ siècle ${ }^{42}$. Les rares églises témoignant de cette inscription de l'alphabet sur les murs ne permettent pas non plus de faire remonter ce rituel avant le $\mathrm{XI}^{\mathrm{e}}$ siècle $^{43}$.

39. "Ordo XLI ", Les Ordines Romani du haut Moyen Âge, ANDRIEU, Michel, Louvain, Spicilegium Sacrum Lovaniense, "Spicilegium Sacrum Lovaniense. Études et documents, fasc. 28 ", 1956, T. IV, p. 319.

40. "Ordo Ambrosianus ad consecrandam ecclesiam et altaria ", éd. MERCATI, Giovanni, Antiche reliquie liturgiche ambrosiane e romane, Rome, Vatican, 1902 (Studi e testi, 7), p. 22. ThurSTON, Herbert, "The alphabet and the consecration of churches ", The Month $115, \mathrm{n}^{\circ} 547$ (1910), p. 622.

41. Thurston, Herbert, "The alphabet and the consecration of churches ", The Month 115, n 547 (1910), p. 621-631. TREFFORT, Cécile, "Opus litterarum. L'inscription alphabétique et le rite de consécration de l'église (IXe-XII ${ }^{\mathrm{e}}$ siècle) ", Cahiers de civilisation médiévale 53 (2010), p. 172-173, revient cependant sur cette attribution, en constatant le vocabulaire latin employé par l'ordo de Lucques, et en faisant le rapprochement entre cet ordo et les ordines espagnols qui comportent tous deux une inscription de l'alphabet sur les murs extérieurs (voir notes suivantes). Elle part aussi du principe que les deux alphabets inscrits sont l'alphabet latin et l'alphabet grec, ce qui permettrait de donner une origine orientale ancienne à ce rituel d'inscription de l'alphabet. Mais l'alphabet grec n'est pas mentionné dans les ordines avant l'époque carolingienne dans le Pontifical Romano-germanique, "Ordo ad benedicandam ecclesiam ", p. 124-173 (Ordo XL), où il est généralement rajouté au texte dans la marge des manuscrits (p. 136 et notes). Trad. REPSHER, Brian, The rite of church dedication in the early medieval era, Lewiston (New York), E. Mellen Pr., 1998, p. 139-169.

42. Gros, Miquel, "El ordo romano-hispanico de Narbona ", Hispania sacra 19 (1966), p. 321-401. Il s'agit du pontifical de Roda, fin du XI ${ }^{\mathrm{e}}$ siècle (Lérida, Arch. Cap. ms 16), du pontifical de Vich, début du XII ${ }^{\mathrm{e}}$ siècle (Vic, Arch. Cap., ms 104 (CV), et de celui de Narbonne, $\mathrm{XI}^{\mathrm{e}}$ siècle, maintenant disparu mais transcrit par dom MARTÈNE, De Antiquis Ecclesiae Ritibus, 1736-1738, Lib. II, Cap. XIII, Ordo VIII.

43. TREFFoRT, Cécile, "Une consécration à la lettre. Place, rôle et autorité des textes inscrits dans la sacralisation de l'église ", et CoDou, Yves, "La consécration du lieu de 
Pour ce qui est de l'inscription de l'alphabet sur le sol, le traité irlandais est le seul à mentionner l'intersection des deux $\mathrm{O}$, ce qui laisse penser que les deux alphabets en question sont des alphabets latins. Le texte précise en effet que les deux $\mathrm{O}$ doivent se croiser au milieu du sol. Cela semble à première vue difficile à réaliser, la lettre $\mathrm{O}$ étant en quatorzième position dans l'alphabet latin de vingt-trois lettres. Cependant, l'alphabet latin présenté dans l'Aureceipt na $n$-Éces, livre d'instruction grammaticale et poétique irlandais qui remonterait au $\mathrm{VII}^{\mathrm{e}}$ siècle, comprend vingt-six lettres, trois signes représentant des abréviations ayant été rajoutés à la fin ${ }^{44}$. Le $\mathrm{O}$ se retrouve ainsi presque au milieu de l'alphabet et l'intersection des deux $\mathrm{O}$ au milieu du sol est donc possible. L'alphabet utilisé dans le traité irlandais pourrait donc être semblable à celui de l'Auraicept na n-Éces. L'ajout des trois abréviations n'est d'ailleurs sans doute pas absolument nécessaire pour croiser ces alphabets à la lettre $\mathrm{O}$, car il suffit d'écrire les lettres de façon plus ou moins serrée. On trouve toutefois un exemple de ces alphabets dans un manuscrit d'Angers, daté de la fin du IX ${ }^{\mathrm{e}}$ siècle $^{45}$. Au folio $9 \mathrm{r}^{\circ}$ se trouve le schéma d'une église comprenant des indications pour la dédicace, il s'agit sans doute d'une des représentations les plus anciennes de cette cérémonie ${ }^{46}$. C'est aussi la seule représentation où sont figurés deux alphabets latins (et non un alphabet latin et un alphabet grec) tracés sur le sol. Ces alphabets comprennent chacun une lettre supplémentaire, l'abréviation \&, et ils se croisent, maladroitement, à la lettre N d'un des alphabets. Il est clair qu'il s'agit d'une maladresse du scribe et que les deux alphabets auraient dû se croiser en $\mathrm{O}$, la diagonale en question n'étant pas tracée de façon droite.

culte et ses traductions graphiques : inscriptions et marques lapidaires dans la Provence des $\mathrm{XI}^{\mathrm{e}}$-XII ${ }^{\mathrm{e}}$ siècles ", Mises en scène et mémoires de la consécration de l'église dans l'Occident médiéval, éd. MéHu, Didier, Turnhout, Brepols, "Centre d'études médiévales de Nice, vol. 7 », 2007, p. 219-252 (voir p. 225-227) et p. 253-284 (voir p. 259-262). TREFFORT, Cécile, "Opus litterarum. L'inscription alphabétique et le rite de consécration de l'église (IX ${ }^{\mathrm{e}}$-XII ${ }^{\mathrm{e}}$ siècle) ", Cahiers de civilisation médiévale 53 (2010), p. 172-173, revient cependant sur cette datation.

44. Auraicept na n-Éces : the scholar's primer, éd. CALDER, George, Edinburgh, J. Grant, 1917, p. 86. Voir aussi The early Irish linguist : an edition of the canonical part of the Auraicept na nÉces, éd. AHLQVIST Anders, Helsinki, Societas Scientiarum Fennica, "Commentationes Humanarum Litterarum, 73, 1982 ", 1983, p. 18 (discussion de la date et de l'auteur de la rédaction) et p. 45-46 (inclusion des alphabets hébraïque, grec et latin dans la partie la plus ancienne).

45. Angers, Bibliothèque Municipale, ms 477 (461). DeufFic Jean-Louis, « La production manuscrite des scriptoria bretons ( $\mathrm{VIII}^{\mathrm{e}}-\mathrm{xl} \mathrm{e}^{\mathrm{e}}$ siècles) ", Landévennec et le monachisme breton dans le haut Moyen Âge : actes du colloque du $15^{e}$ centenaire de l'abbaye de Landévennec, 25-26-27 avril 1985, Landévennec, 1986, p. 293, n 7.

46. Le schéma comporte une triple enceinte de l'église rectangulaire, la porte, l'autel de l'autre côté et les deux alphabets inscrits dans deux bandeaux. Une croix est dessinée à l'angle nord-est, à l'intérieur de l'église. Des instructions sont écrites à l'intérieur de l'église, entre les trois enceintes, à l'extérieur des murs. Voir reproduction en annexe. 


\section{Le manuscrit 477 d'Angers}

Une première analyse, rapide, de ce schéma de dédicace du manuscrit 477 d'Angers ${ }^{47}$, montre de nombreux points communs avec le texte irlandais. En dehors de l'inscription de l'alphabet, une croix est dessinée à l'angle nord-est de l'église, à l'intérieur. Le tour extérieur de l'église porte, inscrits sur deux côtés, le début des psaumes graduels, les inscriptions des deux autres côtés ayant été manifestement effacées en les grattant; on peut cependant en déduire que douze psaumes graduels étaient récités, les psaumes 120 à 131 (119 à 130). Les instructions de la dédicace sont écrites à l'intérieur de l'église, entre les branches du X de l'alphabet, accompagnées du début des psaumes chantés : à droite, à la fin du psaume 119 (118), chanté en entier, le psalmiste à la porte entonne le psaume 24 (23) à partir du verset 8 et l'évêque répond jusqu'à la fin du psaume, il s'agit de l'entrée dans l'église; à gauche, il s'agit de l'aspersion de l'église, appelée baptême, avec de l'eau bénite, accompagnée du psaume 51 (50) en entier; en bas, une antienne (antiphona) tirée du psaume 133 (132) est chanté, puis l'évêque inscrit l'alphabet sur le sol tout en chantant le psaume 87 (86), on récite aussi à ce moment-là treize psaumes de malédiction ${ }^{48}$; en haut, après une autre antienne tirée du psaume 133 (132), l'évêque consacre l'autel en chantant des prières de bénédiction et en récitant des lectures, tout en offrant de l'encens. Il se tient alors devant l'autel, d'autres représentants des ordres de l'Église (diacre, sous-diacre, psalmiste ${ }^{49}$, exorciste, lecteur) se tenant derrière ou sur les côtés. Le prêtre n'est pas mentionné, sans doute parce que l'évêque est lui-même le premier prêtre du diocèse. Une inscription indique que là se trouvent tous les serviteurs du Seigneur. Une autre sur l'autel indique qu'il s'agit de l'autel, c'est-à-dire du siège du Seigneur, et que l'on y opère le mélange d'eau et de vin. Le psaume 134 (133) est mentionné au-dessus de l'autel ${ }^{50}$.

L'inscription de l'alphabet selon les prescriptions du traité, la croix tracée au nord-est, les douze psaumes graduels à l'extérieur, les psaumes de malédiction, ce sont autant de points communs avec le traité irlandais. Le manuscrit 477 d'Angers ${ }^{51}$ est daté de la fin du IX ${ }^{\mathrm{e}}$ siècle (897) pour la

47. Voir l'édition en annexe.

48. Comme dans le traité irlandais, les psaumes de malédiction ne sont pas autrement spécifiés. Seul leur nombre est précisé. Le psautier contient un certain nombre de psaumes dits de "malédiction " ou d' "imprécation ", en tout ou en partie. Les plus couramment cités sont les psaumes $5,17,18,35,40,52,57,58,59,64,68,69,79,83,94$, 109, 120, 129, 137, 140 (numérotation du psautier actuel; il faut enlever 1 pour obtenir la numérotation du psautier de la Vulgate).

49. Il s'agit sans doute ici du chantre, cantor.

50. Des inscriptions à l'intérieur des murs n'ont à première vue rien à voir avec la cérémonie de dédicace. Ce sont de courtes citations d'auteurs classiques, mises bout à bout. Voir leur édition et identification en annexe. Patricia Stirnemann en donne une première analyse dans "L'inscription alphabétique : de la consécration de l'église à l'apprentissage de la lecture et autres usages ", Bulletin monumental, 169-1 (2011), p. 75-76.

51. Catalogue général des manuscrits des bibliothèques publiques de France-Départements, T. 31, 1898, p. 349. OмоNт, Henri, "Glossarium Andegavense, ms 477 (461) de la biblio- 
plus grande part, d'après une glose du folio $21 \mathrm{r}^{\circ}$. Il provient sans doute de l'abbaye de Landévennec ${ }^{52}$, mais est arrivé assez tôt à Saint-Aubin d'Angers, dès le $\mathrm{x}^{\mathrm{e}}$ ou le $\mathrm{xI}^{\mathrm{e}}$ siècle. Le premier cahier de huit feuillets est un glossaire et d'une date différente. Le manuscrit contient principalement plusieurs œuvres scientifiques de Bède le Vénérable sur l'histoire naturelle, l'astronomie et le comput, et des tables de comput. Il contient aussi un très important corpus de gloses en vieux-breton sur ces œuvres de Bède, découvert par Léon Fleuriot ${ }^{53}$. Le schéma de dédicace des églises est sur la première page du manuscrit du Ix ${ }^{\mathrm{e}}$ siècle (folio $9 \mathrm{r}^{\circ}$ ) mais n'est curieusement presque jamais mentionné dans les descriptions du manuscrit $^{54}$. Deux autres textes se trouvent aussi sur cette page ${ }^{55}$, un dans la marge droite, et un deuxième qui commence tout en haut de la page, qui était auparavant écrit sur une grande partie de la page et a été par la suite presque totalement effacé. Lors de la suppression du texte, les intitulés des psaumes graduels en haut et en bas du schéma ont été effacés en même temps. Il est donc probable que le schéma a été copié avant les textes dans les marges, peut-être peu de temps après l'écriture du manuscrit. La réglure verticale du manuscrit correspond au cadre du dessin, et les lignes d'écriture à l'intérieur sont pour la plupart sur les lignes de réglure. L'écriture, petite et nette, est une caroline. Il est donc possible de dater le schéma de dédicace comme le manuscrit, de la fin du IX ${ }^{\mathrm{e}}$ siècle ou du début du $\mathrm{X}^{\mathrm{e}}$ siècle s'il a été copié un peu plus tard.

thèque d'Angers ", Bibliothèque de l'École des Chartes 59/1 (1898), p. 665-688 (description détaillée du contenu du manuscrit p. 665-671). FLEURIOT, Léon, Dictionnaire des gloses en vieux-breton, Paris, Klincksieck, 1964, p. 8-11. Léon Fleuriot donne aussi la description du manuscrit faite par Jean Vezin dans sa thèse dactylographiée de l'Ecole des Chartes, Les Scriptoria d'Angers au XI siècle, Paris, 1958. Mais cette description n'apparaît plus dans la version éditée de sa thèse, Paris, Champion, 1974.

52. Cette hypothèse vient de la liste des saints armoricains insérés dans le calendrier, originaires de la région du Léon : Guénolé, Gueznou, Thégonnec, Meloir, Samson, etc. FLEURIOT, Léon, Dictionnaire des gloses en vieux-breton, Paris, Klincksieck, 1964, p. 8-11.

53. FLEURIOT, Léon, " La découverte de nouvelles gloses en vieux-breton ", Compte-rendu des séances de l'Académie des inscriptions et belles-lettres 103/2 (1959), p. 186-195.

54. Seules exceptions : DeufFIC, Jean-Louis, "La production manuscrite des scriptoria bretons (VIII $-\mathrm{XI}^{\mathrm{e}}$ siècles) ", Landévennec et le monachisme breton dans les haut Moyen Âge : actes du colloque du $15^{e}$ centenaire de l'abbaye de Landévennec, 25-26-27 avril 1985, Landévennec, 1986, p. 293, n 7 . LAMBERT, Pierre-Yves, "Les gloses en vieux-breton aux écrits scientifiques de Bède, dans le manuscrit Angers 477 ", Bède le Vénérable entre tradition et postérité : The Venerable Bede, tradition and posterity: colloque organisé à Villeneuve d'Ascq et Amiens par le CRHEN-O (Université de Lille 3) et Textes, Images et Spiritualité (Université de Picardie-Jules Verne), 3-6 juillet 2002, éd. LEBECQ, Stéphane, PERRIN, Michel, SzERWINIACK, Olivier, Villeneuve-d'Ascq, Université Charles de Gaulle - Lille 3/Ceges, coll. " Histoire de l'Europe du Nord-Ouest, 34 », 2005, p. 309.

55. Ces textes ont été identifiés par Stirnemann, Patricia, "L'inscription alphabétique : de la consécration de l'église à l'apprentissage de la lecture et autres usages ", Bulletin monumental, 169-1 (2011), p. 75-76. Il s'agit pour le texte de la marge de droite d'extraits des Epigrammes de Martial, et pour celui du haut, à moitié effacé, d'un extrait de Jérémie, ch. 9. Ces textes sont à mettre en relation avec les inscriptions dans les murs du schéma (voir édition en annexe). 
Le corpus des gloses bretonnes sur Bède a été comparé avec les commentaires en vieil-irlandais sur le même auteur ${ }^{56}$. Le résultat montre clairement qu'une bonne partie du commentaire de ce manuscrit est empruntée à une tradition irlandaise. De plus, on trouve dans une des tables pascales du manuscrit l'obit d'un saint irlandais d'origine bretonne, Finian de Clonard (Uuiniaus) ${ }^{57}$. Enfin, le manuscrit 477 d'Angers contient un commentaire marginal à Bède qui dérive en grande partie d'un traité irlandais sur le comput du $\mathrm{VII}^{\mathrm{e}}$ siècle issu du cercle de Cummianus et écrit non loin de Clonard ${ }^{58}$. L'ensemble du manuscrit est ainsi marqué d'influences irlandaises, et il n'est pas interdit de penser qu'il a été copié d'un exemplaire irlandais ou est passé par des mains irlandaises ${ }^{59}$. Il est donc légitime de supposer que le schéma de dédicace d'église folio $9 \mathrm{r}^{\circ}$ puisse être une version antérieure, datée du IX ${ }^{\mathrm{e}}$ siècle, et plus brève car ce n'est pas un ordo, du traité irlandais du $\mathrm{XI}^{\mathrm{e}}$ siècle, ce qui permettrait ainsi de reculer la date du traité d'autant. Les premiers indices donnés par le dessin devraient pouvoir être confirmés par d'autres dans la suite de l'analyse de l'ordo irlandais.

\section{Tour de l'église et psaumes graduels}

La troisième partie du traité, le tour de l'église avec la récitation des douze psaumes, est spécifique au traité irlandais et au schéma du manuscrit d'Angers, et il faut la séparer du rite d'aspersion des murs. La façon dont les psaumes sont récités, par groupes de trois, une antienne d'abord prise au troisième psaume avant de réciter le groupe de trois, semble correspondre à ce que saint Colomban appelle dans sa " Règle des moines " un " chœur ", groupe de trois psaumes dont le troisième est antiphoné60. Les

56. LAMBERT, Pierre-Yves, " Les commentaires celtiques à Bède le Vénérable ", Études celtiques 20 (1983), p. 119-143 et 21 (1984), p. 185-206. LAMBERT, Pierre-Yves, "Les gloses en vieux-breton aux écrits scientifiques de Bède, dans le manuscrit Angers 477 ", Bède le Vénérable entre tradition et postérité : The Venerable Bede, tradition and posterity : colloque organisé à Villeneuve d'Ascq et Amiens par le CRHEN-O (Université de Lille 3) et Textes, Images et Spiritualité (Université de Picardie-Jules Verne), 3-6 juillet 2002, éd. LEBECQ, Stéphane, PERRIN, Michel, SzERWINIACK, Olivier, Villeneuve d'Ascq, Université Charles de Gaulle- Lille 3/Ceges, "Coll. Histoire de l'Europe du Nord-Ouest, 34 ", 2005, p. 309-319.

57. O'CRÓINín, Dáibhi, " Early Irish annals from Easter-tables : a case restated ", Peritia 2 (1983), p. 74-86. Voir LAMBERT, Pierre-Yves, "Les commentaires celtiques à Bède le Vénérable ", Études celtiques 21 (1984), p. 202.

58. O'CRÓINín, Dáibhi, " Early Irish annals from Easter-tables : a case restated ", Peritia 2 (1983), p. 79; The Munich computus: text and translation. Irish computistics between Isidore of Seville and the Venerable Bede and its reception in Carolingian times, éd. WARNTJEs, Immo, Stuttgart, Franz Steiner Vg, "Sudhoofs Archiv 59, Zeitschrift für Wissenschaftgeschichte", 2010, p. CLXXXIII-CLXXXVII (édition des gloses d'Angers concernant le comput de Munich).

O’CRóinín, Dáibhi, "A seventh-century Irish computus from the circle of Cummianus ", Proceedings of the Royal Irish Academy (PRIA) 82C (1982), p. 405-430.

59. O'CRóInín, Dáibhi, " Early Irish annals from Easter-tables : a case restated ", Peritia 2 (1983), p. 79.

60. "Regula monachorum ", Sancti Columbani Opera, éd. WALKER G. S. M., Dublin, DIAS, "Scriptores Latini Hiberniae, vol. II ", 1970, ch. VII, p. 130 et p. 131, note 1. Saint CoLOMBAN, Règles et pénitentiels monastiques, trad. VoGÜE, Adalbert de, Bégrolles-en-Mauges, Abbaye 
psaumes, regroupés par multiples de trois, étaient récités pendant l'office monastique, à chaque heure canonique, de façon à ce que l'ensemble du psautier soit récité chaque jour. La division de la psalmodie en " chœur " et la division de chaque " chœur " en une proportion de deux psaumes sur un étaient générales dans les ordines monastiques occidentaux. Mais chaque règle avait sa variante et celle donnée dans la "Règle des moines " de saint Colomban est spécifique, on ne la retrouve dans aucune autre règle ${ }^{61}$. C'est la même, par contre, qui est utilisée dans l'Antiphonaire de Bangor, écrit un siècle après la règle de Colomban. La psalmodie telle qu'elle est présentée dans le traité de consécration des églises est donc ancienne, puisqu'elle remonte au $\mathrm{VI}^{\mathrm{e}}$ siècle au moins, et spécifique à l'Irlande. La récitation de prières après le chant de psaumes se retrouve aussi dans la "Règle conventuelle " de saint Colomban ${ }^{62}$ : la prière est courte, silencieuse, et accompagnée d'une génuflexion. Les deux prières qui complètent la psalmodie de la circumambulation, le Gloria et le Sicut erat in principio nunc et semper, sont également courtes. Même si ces prières sont chantées et non récitées silencieusement, on peut sans doute rapprocher le processus de celui décrit par Colomban. Dans l'ensemble, la technique de récitation des psaumes et des prières remontent donc $\mathrm{au} \mathrm{VI}^{\mathrm{e}}$ siècle au moins, et on peut se demander si le reste de cette partie du rituel de consécration spécifique au traité irlandais, c'est-à-dire la circumambulation, le choix de douze psaumes graduels, et la gravure des croix sur les murs n'est pas aussi ancienne.

\section{Aspersions et exorcismes}

Le rite d'aspersion des murs est lui aussi très ancien, il est attesté en Espagne dès le $\mathrm{VI}^{\mathrm{e}}$ siècle pour exorciser une église, mais n'était pas d'usage à Rome, comme le montre la réponse du pape Vigile à Profuturus de Braga, en $538^{63}$. La consécration de l'eau, au début de la cérémonie, qui servira plus tard à l'aspersion de l'église, mêlée de sel dans le rite irlandais, est

de Bellefontaine, "Aux sources du monachisme colombanien II. Vie monastique n 20 ", 1989, p. 60, ch. VII, §5-6 et p. 22.

61. CURRAN, Michael, The antiphonary of Bangor and the early Irish monastic liturgy, Blackrock, Irish Academic Press, 1984, p. 166-167.

62. CURRAN, Michael, The antiphonary of Bangor and the early Irish monastic liturgy, Blackrock, Irish Academic Press, 1984, p. 168. "Regula coenobialis ", Sancti Columbani Opera, éd. WalKer G. S. M., Dublin, DIAS, " Scriptores Latini Hiberniae, vol. II ", 1970, § II, p. 146, l. 16-18; § IX, p. 158, l. 13-21. Saint ColomBan, Règles et pénitentiels monastiques, trad. VoGÜE, Adalbert de, Bégrolles-en-Mauges, Abbaye de Bellefontaine, "Aux sources du monachisme colombanien II. Vie monastique ${ }^{\circ} 20$ ", 1989, p. 121, § II, 6; p. 130-131, $\S \mathrm{IX}, 9-11$.

63. Le Liber Ordinum en usage dans l'Eglise wisigothique et mozarabe d'Espagne du $V^{e}$ au XI siècle, éd. FerOtin, D. Marius, Paris, F. Didot, 1904, col. 507 (" Appendice III. La dédicace des églises chez les Wisigoths ", col. 506-515). Les Ordines Romani du haut Moyen Âge, éd. ANDRIEU, Michel, Louvain, Spicilegium Sacrum Lovaniense, "Spicilegium Sacrum Lovaniense. Études et documents, fasc. 28 », 1956, T. IV, p. 323, 372-373. DucHESNE, Louis, Origines du culte chrétien : étude sur la liturgie latine avant Charlemagne, Paris, De Boccard, 1925 (5 éd.), p. 425. 
manifestement l'eau qui sert aux exorcismes, comme dans la cérémonie du baptême. Le schéma du manuscrit d'Angers utilise d'ailleurs le terme "baptiser " (babtizote) au moment de l'aspersion de l'église. Elle est suivie de psaumes et de prières d'expulsion et de malédiction des démons. On retrouve une prière d'exorcisme dans l'ordo 41, mais il s'agit d'une formule courte et non de psaumes, encore moins de 13 psaumes comme le signale le schéma du manuscrit d'Angers. Le Sacramentaire de Gellone donne le texte de plusieurs prières de bénédiction et d'exorcismes de l'eau, du sel, et de l'eau et du sel ${ }^{64}$. L'ordo 40 du Pontifical Romano-Germanique prévoit quant à lui un premier mélange d'eau et de sel bénits, suivi de prières d'exorcisme, sous la tente des reliques, avant d'entrer dans l'église. Cette première bénédiction est ajoutée par rapport au texte de l'ordo 41, et fait double emploi avec le mélange d'eau, de sel, de cendres et de vin qui est décrit plus loin. Les bénédictions et exorcismes sont précédés dans le Pontifical d'une litanie qui montre une influence irlandaise, sainte Brigitte et saint Columba étant invoqués, ainsi que saint Kilian ${ }^{65}$. Il est donc possible que cette première bénédiction provienne d'un usage irlandais.

L'eau est mélangée de sel et de cendres, auquel on rajoute le vin après la prière d'exorcisme dans l'ordo $41^{66}$. La cendre était aussi répandue sur le sol pour pouvoir écrire l'alphabet dans les ordines plus tardifs (Lucques). Mais il n'y a aucune utilisation de la cendre dans le rite irlandais. Le rite byzantin utilise aussi du vin, mais non mélangé, pour en asperger l'autel ${ }^{67}$. C'est sans doute un mélange des deux rites que présente le traité irlandais quand il consacre une deuxième fois de l'eau, mélangée à du vin, avec l'ajout de l'hostie. Ce mélange a lieu au début de la consécration de l'autel, avec comme justification que l'hostie et le vin servent à chaque messe. Cette eau ne servira qu'à la consécration de l'autel. Le rite irlandais reprend aussi du rite byzantin les trois croix tracées sur l'autel, auxquelles il adjoint les quatre croix aux angles du rite gallican. L'onction de l'autel et de l'église avec de l'huile provient du rite byzantin, où elle est mentionnée au Ive siècle, on la retrouve dans les deux rites gallican et irlandais. En Gaule, l'onction de l'autel est mentionnée dès le vi ${ }^{\mathrm{e}}$ siècle, au concile d'Agde de $506^{68}$. C'est

64. Liber Sacramentorum Gellonensis, éd. Dumas, A., Turnhout, Brepols, "Corpus Christianorum Series Latina, 159 », 1981, p. 360-362.

65. Le moine irlandais Kilian est l'apôtre de la Franconie (Würzburg) à la fin du vII ${ }^{\mathrm{e}}$ siècle. Pour une première approche, voir PRINZ, Franz, Frühes Mönchtum im Frankenreich, München, 1965, p. 239-241. Voir aussi l'article et la bibliographie d'Alfred Wendehorst dans le Lexikon des Mittelalters et celui de Geneviève BüHRER-THIERRY dans Encyclopedia of the Middle Ages, T. 1, 2000, p. 802.

66. "Ordo XLI ", Les Ordines Romani du haut Moyen Âge, éd. ANDRIEU, Michel, Louvain, Spicilegium Sacrum Lovaniense, "Spicilegium Sacrum Lovaniense. Études et documents, fasc. 28 ", 1956, T. IV, p. 323 et 341-342, § 7-10.

67. L'Eucologio Barberini gr. 336, éd. PARENTI, Stefano, VelKovsKa, Elena, Rome, CLV-Ed. Liturgiche, 2000, p. 160, trad. p. 329, § 152/1.

68. " Ordo XLI ", Les Ordines Romani du haut Moyen Âge, éd. ANDRIEU, Michel, Louvain, Spicilegium Sacrum Lovaniense, "Spicilegium Sacrum Lovaniense. Études et documents, fasc. 28 ", 1956, T. IV, p. 324-326. 
la même chose pour l'emploi de l'encens sur l'autel. Le traité irlandais est par ailleurs le seul texte liturgique irlandais où l'encens apparaît ${ }^{69}$.

Tel qu'il se présente, le traité irlandais contient des éléments très anciens, datés du $\mathrm{VI}^{\mathrm{e}}$ siècle au plus tôt, certains spécifiques à l'Irlande, les autres pour la plupart conformes au rite gallican de la dédicace des églises, avec des influences orientales. Ces rites, contrairement au rite romain, ont été qualifiés de baptismaux, car ils reproduisent dans l'ensemble la cérémonie du baptême (exorcismes, aspersion, onction, chrismation) ${ }^{70}$. Le rite romain, tourné principalement vers la consécration des reliques, est vu comme un rite funéraire. L'élaboration des ordines romains, au VIII ${ }^{\mathrm{e}}$ siècle, s'est faite sous l'influence des rites gallicans et les plus anciens ordines conservés, romains ou gallicans, traitent ensemble la consécration des reliques et de l'église. Le seul ordo ne parlant pas de la consécration des reliques est celui du rite ambrosien du manuscrit de Lucques. Le rite byzantin séparait quant à lui les deux cérémonies. Or, le traité ne concerne que la consécration de l'église et de l'autel. On n'y parle aucunement de la consécration des reliques. On a voulu y voir l'indice que les Irlandais, et les Bretons avant eux, ne pratiquaient la dédicace de l'église qu'aux saints encore vivants ${ }^{71}$.

\section{Les témoignages des textes hagiographiques}

\section{Le pèlerinage au tombeau et les psaumes graduels}

Les Irlandais pratiquaient le culte des reliques ${ }^{72}$, mais celui-ci semble avoir pour origine le culte du tombeau du saint fondateur de l'église ou de l'abbaye, qui était situé dans le cimetière, appelé reilic, dès la fin du $\mathrm{VII}^{\mathrm{e}}$ siècle, dans le récit de Tirechán ${ }^{73}$. Ce culte existait d'ailleurs aussi à Rome, où la construction d'oratoires et de basiliques près ou au-des-

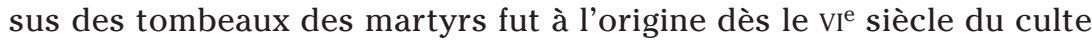
des reliques ${ }^{74}$. En Irlande, il donna naissance très tôt à des pèlerinages, appelés an turas, à plusieurs stations marquées par des stèles ou des croix, et qui commençaient et se terminaient à la tombe ou à l'oratoire

69. Warren, F. E., The liturgy and ritual of the Celtic church, $2^{\mathrm{e}}$ éd. Stevenson, Jane, Woodbridge, Boydell Pr., 1987 (1 ${ }^{\text {re }}$ éd. Oxford 1881), p. 127.

70. DuCHESNe, Louis, Origines du culte chrétien : étude sur la liturgie latine avant Charlemagne, Paris, De Boccard, 1925 (5 éd.), p. 455. REPSHER, Brian, The rite of church dedication in the early medieval era, Lewiston (New York), E. Mellen Pr., 1998, p. 113-128.

71. "On an early Irish tract in the Leabhar Breac describing the mode of consecrating a church ", éd. OLdEN, Thos., Transactions of the St Paul's ecclesiastical society IV (1897), p. 99 .

72. PICARD, Jean-Michel, "Le culte des reliques en Irlande ", Les reliques : objets, cultes, symboles, actes du coll. int., Boulogne-sur-Mer, 4-6 sept. 1997, éd. BozóKY, Edina, Helvetius, Anne-Marie, Turnhout, Brepols, 1999, p. 39-55 (voir p. 43).

73. The Patrician texts in the Book of Armagh, éd. BIELER, Ludwig, Dublin, DIAS, 1979, $\S 26 / 20$, p. 144.

74. PuniET, Pierre de, " Dédicace des églises ", DACL, 1920, T. 4, col. 383. 
dressé auprès d'elle ${ }^{75}$. À partir du VII ${ }^{\mathrm{e}}$ siècle au moins, au moment des premières disputes sur la date de Pâques ${ }^{76}$, on prit l'habitude de rapporter des reliques de Rome, les plus importantes ayant été rapportées à Armagh ${ }^{77}$, puis de translater les reliques des saints locaux ${ }^{78}$ et de placer, dans des basiliques (basilica) construites à cet effet, les tombes des rois ou des saints. Les basiliques sont à l'origine, en Irlande comme en Gaule, les cimetières où reposent les rois puis les oratoires construits dans des cimetières, avant d'être de riches églises telle celle décrite dans la "Vie de Brigitte " par Cogitosus ${ }^{79}$.

Le culte des reliques n'est donc pas ignoré de l'Irlande et des îles Britanniques, mais il conserva la forme première du pèlerinage au tombeau. Si le traité irlandais ne parle pas de la consécration des reliques, c'est parce que le corps du saint n'était pas dispersé dans de multiples églises, mais translaté dans son intégralité ${ }^{80}$. Bède évoque la construction d'églises, en Grande Bretagne, où le corps du saint, Augustin à Cantorbéry, Aidan à Lindisfarne, fut enterré après la consécration de l'église ${ }^{81}$. À Kildare, Cogitosus décrit les deux tombes de Brigitte et Conlaed disposées de part et d'autre de l'autel ${ }^{82}$. Si, au viI ${ }^{\mathrm{e}}$ siècle, Armagh justifie sa primauté sur les églises d'Irlande par l'importance des reliques qu'elle possède, celles des saints Pierre et Paul, Stéphane et Laurent, ainsi que, par faveur secrète, un peu de sang du Christ conservé dans un tissu de $\operatorname{lin}^{83}$, c'est parce qu'on ignore alors où se trouve le corps de Patrick.

On retrouve la trace d'un rituel de vénération des reliques, sous la forme du culte rendu auprès du tombeau du saint, à la fin du Liber Angeli écrit

75. HERITY, Michael, "The antiquity of an turas (the pilgrimage round) in Ireland ", Lateinische Kultur im VIII. Jahrhundert, Eos Vg, 1989, p. 95-144.

76. PICARD, Jean-Michel, "Le culte des reliques en Irlande ", Les reliques : objets, cultes, symboles, actes du coll. int. Boulogne-sur-Mer, 4-6 sept. 1997, éd. BozóKY, Edina, HelvETIus, Anne-Marie, Turnhout, Brepols, 1999, p. 43. DoHERTy, Charles, "The basilica in early Ireland ", Peritia 3 (1984), p. 303-315 (voir p. 310).

77. The Patrician texts in the Book of Armagh, éd. BIELER, Ludwig, Dublin, DIAS, 1979, $\S 16 / 5$, p. 184-191 ("Liber Angeli").

78. Die irische Kanonensammlung, éd. WASSERSCHLEBEn, Heinrich, Leipzig, B. Tauchnitz, 1885, Liber XLIX, justifie ces pratiques et le culte des reliques.

79. DoherTy, Charles, "The basilica in early Ireland ", Peritia 3 (1984), p. 303-315 (en particulier p. 313-314). LECLERCQ, Henri, " Basilique », DACL II, col. 525-602.

80. O'CARRAGÁIn, Tomás, Churches in Early medieval Ireland : architecture, ritual and memory, Newhaven, London, Yale University Pr., 2010, p. 83.

81. BÈDE LE VÉNÉRABle, Histoire ecclésiastique du peuple anglais, éd. LAPIDGE, Michael, trad. Monat, Pierre, Robin, Philippe, intr. et notes CRÉPIn, André, Paris, Le Cerf, "Sources Chrétiennes n 489, 490, 491 ", 2005, T. 2, 3; 3, 17.

82. "Vita II S. Brigidae Virg., auctore, ut creditur, Cogitoso ", Acta Sanctorum Februarii, Anvers, 1658 (réimpr. Bruxelles, 1960), p. 135-141. "Cogitosus, Life of Brigit ", trad. CONNOLly, Séan, PICARD, Jean-Michel, Journal of the Royal Society of Antiquaries of Ireland 117 (1987).

83. The Patrician texts in the Book of Armagh, éd. BIELER, Ludwig, Dublin, DIAS, 1979, "Liber Angeli ", p. 189, § 19. 
par Tirechán vers 678-687 ${ }^{84}$. Celui-ci rappelle en effet la prescription des prières qui devaient être dites chaque dimanche à Armagh, en allant rendre un culte aux reliques et en en revenant : "Une règle de prière : chaque dimanche à Armagh, en allant à l'écrin des martyrs et en en retournant, c'est-à-dire, "Domine clamavi ad te" jusqu'à la fin, "Ut quid Deus repulisti" jusqu'à la fin, et "Beati immaculati” jusqu'à la fin de la bénédiction, et les quinze psaumes graduels ${ }^{85}$. " Les prières mentionnées sont les psaumes 141 (140) ('Domine...', prière d'un persécuté), 74 (73) (“Ut quid....", sur le sanctuaire de Dieu profané), 119 (118) (“Beati immaculati...", psaume d'instruction sur la loi divine, appelé abécédaire car c'est un psaume alphabétique de 22 strophes correspondant aux 22 lettres de l'alphabet hébreu) et les psaumes 120 à 134 (119 à 133 selon la Vulgate), appelés psaumes graduels. Or, le traité sur la consécration de l'église qui donne le détail des prières devant être récitées lors de la consécration proprement dite de l'église, après celle du sol et celle de l'autel, évoque aussi les psaumes graduels. L'évêque progresse de point cardinal en point cardinal en chantant douze psaumes graduels sur les quinze. Le manuscrit d'Angers, lui aussi, note douze psaumes graduels.

La récitation des psaumes graduels est tout à fait appropriée pour la dédicace des églises. En effet, ces psaumes 120 à 134 (119 à 133), appelés encore psaumes des montées, étaient récités lors du pèlerinage annuel des Juifs au Temple de Jérusalem. Ils commémoraient le retour de l'exil de Babylone (en plaine) à Jérusalem (750m d'altitude), et la construction du nouveau temple qui suivit. Réciter ces psaumes évoque donc à la fois la montée vers Jérusalem, la terre promise, et la construction du temple : c'est l'interprétation, dite historique, de l'école exégétique d'Antioche, représentée par Théodore de Mopsueste, dont le commentaire sur les psaumes, traduit en latin par Julien d'Eclane ${ }^{86}$, fut repris et commenté en Irlande aux $\mathrm{VII}^{\mathrm{e}}$ et $\mathrm{VIII}^{\mathrm{e}}$ siècles. Cette tradition exégétique est propre à l'Irlande, et les manuscrits transmettant le commentaire de Théodore de Mopsueste sont presque tous d'origine irlandaise ${ }^{87}$. Une autre interprétation y voit la montée des quinze marches du temple de Salomon. Une troisième interprétation, celle de Jérôme et d'Augustin en particulier, et qu'on rencontre

84. Charles-Edwards, Thomas M., Early Christian Ireland, Cambridge, University Press, 2000, chap. 10, p. 436-440. Le Liber Angeli était jusque là daté de 630-640.

85. The Patrician texts in the Book of Armagh, éd. BIELER, Ludwig, Dublin, DIAS, 1979, "Liber Angeli ", p. 190, § XI 2/31: Fundamentum orationis: in unaquaque die dominica in Alto Machae ad sargifagum martyrum adeundum ab eoque reuertendum, id est 'Domine clamaui ad te' usque in finem, 'Ut quid Deus repulisti' in finem, et 'Beati immaculati' usque in finem benedictionis et quindecim psalmi graduum.

86. ThÉOdore De Mopsueste, Expositionis in psalmos, Iuliano Aeclanensi interprete in latinum versae quae supersunt, éd. DE CONINCK, Lucas, D’HonT, Maria Josepha, Turnhout, Brepols, "CCSL 88A », 1977.

87. Glossa in psalmos : the Hiberno-Latin gloss on the psalms of Codex Palatinus Latinus 68 (Psalms 39 : 11-151 : 7), éd. McNAmara, Martin, Rome, Vatican, "Studi e Testi, 310 ", 1986, p. 70-75. 
aussi dans les commentaires irlandais, y voit l'ascension du chrétien ou de l'âme vers Dieu ${ }^{88}$.

La récitation de ces psaumes n'apparaît cependant dans aucun des sacramentaires ou pontificaux occidentaux, en dehors du traité irlandais et du schéma de dédicace du manuscrit d'Angers. Aussi est-il particulièrement intéressant de retrouver la mention de leur récitation dans un texte datant du vII ${ }^{\mathrm{e}}$ siècle, c'est-à-dire avant l'élaboration de l'ordo sur la consécration des églises. Cette application liturgique correspond à la tradition exégétique des psaumes propre à l'Irlande. La circumambulation de l'église avec récitation des psaumes graduels est d'ailleurs la partie la plus développée du traité sur la consécration des églises, celle où il est question de discussions autour de plusieurs traditions différentes et celle où la totalité des prières et des psaumes récités est expliquée dans le détail plutôt que de se référer au contenu du livre de l'évêque. Elle est donc très importante pour le rédacteur du traité.

L'application liturgique la plus ancienne que l'on connaisse de la récitation des psaumes graduels est celle de la préparation romaine à Pâques, pendant la période de préparation des catéchumènes au baptême. C'est un usage local, limité à Rome, et dont l'origine est antérieure au $\mathrm{V}^{\mathrm{e}}$ siècle $^{89}$. Les six premiers psaumes graduels étaient utilisés pendant les deux premières semaines du carême romain primitif de trois semaines, la dernière semaine étant la semaine pascale. Le carême était entièrement dévolu à la préparation baptismale, le baptême étant conçu comme une montée vers Dieu, une seconde naissance : on retrouve ici une des interprétations des psaumes des montées. Quand le carême s'allongea à quarante jours, six semaines, au $\mathrm{Vl}^{\mathrm{e}}$ siècle, on utilisa les autres psaumes des montées pour l'ensemble des cinq semaines précédant la semaine pascale. La récitation des psaumes graduels pendant le carême fit ensuite partie de l'usage monastique en Occident.

Tirechán prescrit la récitation de trois autres psaumes pendant la visite dominicale aux reliques d'Armagh (ps. 140, 73 et 118). Parmi ceux-ci, la récitation du psaume 141 (140) est utilisée dans le traité irlandais pour la consécration de l'autel. Un deuxième, le psaume 119 (118) est récité dans le rite ambrosien de Lucques de la dédicace d'église au moment où l'évêque inscrit l'alphabet sur le sol de l'église ${ }^{90}$. C'est le seul ordo qui signale la récitation d'un psaume pendant l'écriture de l'alphabet, ce qui a fait dire que cette partie de la cérémonie se déroulait en silence ${ }^{91}$. Cette association est cohérente,

88. Sur l'exégèse des psaumes graduels, voir HocKEY F., "Cantica graduum. The gradual psalms in Patristic tradition ", Studia patristica 10/1 (1970), p. 355-359.

89. ClaiRE, Jean, "Les psaumes graduels au cour de la liturgie quadragésimale ", Revue grégorienne 21 (1986), p. 5-12. BERNARD, Philippe, Du chant romain au chant grégorien (IV ${ }^{e}$ XII ${ }^{e}$ siècle), Paris, Le Cerf, "Patrimoines. Christianisme », 1996, p. 179-193.

90. "Ordo Ambrosianus ad consecrandam ecclesiam et altaria ", éd. MERCATI, Giovanni, Antiche reliquie liturgiche ambrosiane e romane, Rome, Vatican, "Studi e testi, 7 ", 1902 , p. 22. Thurston, Herbert, "The alphabet and the consecration of churches ", The Month $115, \mathrm{n}^{\circ} 547$ (1910), p. 621-631 (voir p. 622).

91. MÁRKUS, Gilbert, "What were Patrick's alphabets? ", Cambrian Medieval Celtic Studies 31 (1996, Summer), p. 1-15 (voir p. 5). LECLERCQ, Henri, «Abécédaire », DACL, 1907, T. I, col. 58. 
puisque le psaume 119 (118) est à l'origine, en hébreu, alphabétique. Mais le traité irlandais ne précise pas s'il faut réciter un psaume au moment de l'écriture de l'alphabet. Le manuscrit d'Angers semble montrer par contre que l'écriture de l'alphabet s'accompagnait du psaume 87 (86) puis de psaumes de malédictions, et que le psaume 119 (118) était récité dans son entier avant l'arrivée de l'évêque devant la porte et son entrée dans l'église. Cela correspondrait davantage avec les prescriptions de Tirechán.

Tirechán ne donne pas d'indication supplémentaire sur le circuit à effectuer. Toutefois, il est manifeste qu'on a chez Tirechán la description d'un pèlerinage au tombeau d'un saint (an turas). Une mention marginale glosant "l'écrin des martyrs ", sargifagum martyrum, en duferti martar, " la tombe des martyrs ${ }^{92}$ ", qui reprend le terme irlandais, fert, désignant la tombe, le prouve. Il s'agit du premier emplacement donné à Patrick par le roi Daire, là où, selon Muirchu, il y aurait eu la tombe des martyrs ${ }^{93}$, situé au pied de la colline d'Armagh, en dehors de l'enceinte monastique, à l'endroit où on a retrouvé des tombes ${ }^{94}$. Plus tard, il y eut sans doute une église construite à l'emplacement des tombes, car les Annales évoquent le [Tempul] na Ferta (" [Eglise] des reliques ") ${ }^{95}$. Tirechán fait donc référence à l'ancienne vénération du tombeau des saints, et il est vraisemblable que le circuit de pèlerinage ait continué à exister lorsque les reliques furent transférées à l'intérieur de l'église. La visite dominicale aux reliques d'Armagh se déroulait donc sans doute avec comme point de départ l'église située en haut de la colline, selon des stations qu'on imagine sur le trajet jusqu'en bas de la colline, puis faisant le tour du tombeau et de l'enceinte de l'ancien fort ${ }^{96}$, reprenant le schéma des anciens pèlerinages autour de la tombe. La récitation des psaumes suppose d'ailleurs un circuit assez long ${ }^{97}$.

92. The Patrician texts in the Book of Armagh, éd. Bieler, Ludwig, Dublin, DIAS, 1979, p. 241 , note sur le $\S$ XI $2 / 31$.

93. The Patrician texts in the Book of Armagh, éd. BIELER, Ludwig, Dublin, DIAS, 1979, p. 99-101, ch. I 24.

94. Artchison, Nicholas B., Armagh and the royal centres in early medieval Ireland : monuments, cosmology and the past, Woodbridge, Boydell \& Brewer, Cruithne Pr., 1994, p. 202. Aitchison cite les recherches de LyNN, Christopher J., " Excavations at 46-48 Scotch Street, Armagh ", Ulster Journal of Archaeology 51 (1988), p. 69-84.

95. The Annals of Inisfallen (MS Rawlinson B503), éd. MAC AIRT, Séan, Dublin, Dublin Institute for Advanced Studies, 1951, année 1095, p. 250, § 13. Annála Uladh, Annals of Ulster, otherwise Annála Senait, Annals of Senat : a chronicle of Irish affairs from AD 431 to $A D$ 1540, éd. Hennessy, William M., MACCARTHY, Bartholomew, Dublin, HMSO, 1887-1901, vol. 2, p. 529 (année 1095) et vol. 3, p. 195 (année 1179). Voir Aitchison, Nicholas B., Armagh and the royal centres in early medieval Ireland: monuments, cosmology and the past, Woodbridge, Boydell \& Brewer, Cruithne Pr., 1994, p. 202.

96. Artchison, Nicholas B., Armagh and the royal centres in early medieval Ireland : monuments, cosmology and the past, Woodbridge, Boydell \& Brewer, Cruithne Pr., 1994, p. 215219, fig. 52-55 (plans d'Armagh).

97. Artchison, Nicholas B., Armagh and the royal centres in early medieval Ireland : monuments, cosmology and the past, Woodbridge, Boydell \& Brewer, Cruithne Pr., 1994, p. 267, d'après C. J. Lynn. 


\section{An turas et troménies}

Les sites anciens de pèlerinages analysés par M. Herity ${ }^{98}$, tous datés du début du $\mathrm{VI}^{\mathrm{e}}$ siècle au début du viII ${ }^{\mathrm{e}}$ siècle au plus tard, confirment à la fois le texte de Tirechán et le traité de consécration des églises. Le tour commence au tombeau du saint ou dans l'oratoire, situé dans l'enceinte monastique : il s'effectue par la droite, comme le tour de l'église dans le rite de la dédicace, et le pèlerin va de station en station. Les stations sont marquées par des croix devant lesquelles des prières sont récitées. Ces prières sont en général des Credo, des Pater ou des Ave Maria, mais il est possible que d'autres prières aient été récitées anciennement : dans ces sites de pèlerinage, en effet, les stations sont au nombre de quinze (une seizième station est en fait le retour à la première), comme les psaumes graduels. À Inismurray ${ }^{99}$, le an turas fait le tour de l'île, le plus près possible du rivage, et on peut en déduire que le circuit faisait sans doute le tour du termon, du domaine, du site monastique. C'est ce qui est attesté dans le terme breton " troménie ", tour du minihi ou domaine monastique, opéré périodiquement en procession ${ }^{100}$. Dans la troménie bretonne, les reliques sont portées de station en station, et un autre nom pour ce pèlerinage est celui de tro ar relegoú, " tour des reliques ${ }^{101}$ ".

Le traité irlandais rapproche d'ailleurs la consécration de l'église de sa délimitation, tórann dans le traité irlandais ${ }^{102}$. Tórann traduit par " délimitation; limite, frontière; signe ${ }^{103}$ ", est aussi le terme utilisé lors de la délimitation par le saint du domaine de son monastère ou de son église avec le cimetière ${ }^{104}$.

98. HERITY, Michael, "The antiquity of an turas (the pilgrimage round) in Ireland ", Lateinische Kultur im VIII. Jahrhundert, Eos Vg, 1989, p. 95-144. Les sites étudiés sont Glencolumbkille (co. Donegal), et les îles de Rathlin O'Birne (co. Donegal), Inismurray (co. Sligo), Caher Island (co. Mayo), Tory Island (co. Donegal) et Ardoileán (co. Galway).

99. O'SUllivan Jerry, Ó CARRAGÁIN Tomás, Inishmurray: monks and pilgrims in an Atlantic landscape, Cork, Collins Press, "Archaeological surveys and excavations, 1997-2000; vol. 1 ", 2008.

100. LAURENT, Donatien, " Le juste milieu. Réflexion sur un rituel de circumambulation millénaire : la troménie de Locronan ", Tradition et histoire dans la culture populaire : rencontres autour de l'œuvre de Jean-Michel Guilcher, Grenoble, Musée Dauphinois, 20-21 janvier 1989, Grenoble, Centre alpin et rhodanien d'ethnologie, 1990, p. 255-292.

101. HascoËT, Joël, La troménie de Landeleau, ou le Tro ar Relegoú (le tour des reliques), Landeleau, Kan an Douar, 2002, p. 14.

102. "The Lebar Brecc Tractate on the consecration of a church ", éd. STOKES, Whitley, Miscellanea linguistica in onore di Graziado Ascoli, Turin, 1901 (repr. Slatkine, 1973), p. 366, $\S 1$ : Line andso dorigensat hécnaide eolcha um chairechtair toraind n-eclasi, do erslocud eolais coisecartha eclasi no daurthaige nui. Trad. : "A tractate, here, which wise men, learned as to the characteristics of marking out a church, have composed in order to expound the science of consecrating a new church or oratory".

103. BERGIN, Osborn, "Modern Irish teóra, 'limit, border' ", Eriu 7 (1913-1914), p. 27-29. Lexique étymologique de l'irlandais ancien, éd. VENDRYES, Joseph, puis BACHELLERY, Edouard, LAMBERT, Pierre-Yves, Paris, CNRS, Dublin, DIAS, 1978, T-113-114. DIL, vol. to-tu, col. 255-256. 104. Beatha Bharra : Saint Finbarr of Cork, the complete life, éd. O'RiaIn, Pádraig, London, Irish Texts Society, "Irish Texts Society, vol. 57 », 1994, p. 64-65. Bethu Phâtraic, The Tripartite life of Patrick : texts and sources, Mulchrone, Kathleen, Dublin, Hodges Figgis and co.; London, Williams and Norgate, 1939, p. 136, 1. 2735-6. 
On retrouve ce terme dans les Additamenta du Livre d'Armagh, du $\mathrm{VIII}^{\mathrm{e}}$ siècle, écrits en partie en irlandais, lorsque Fiacc demande à l'ange que saint Patrick vienne délimiter le monastère désigné par un sanglier et une biche : " Fiacc dit à l'ange qu'il n'irait pas là-bas tant que Patrick ne viendrait pas pour délimiter son bout de terrain pour lui et le consacrer, et que ce serait de lui qu'il recevrait sa terre ${ }^{105}$. " Fiacc aurait pu consacrer l'endroit lui-même, car Patrick l'avait ordonné évêque ${ }^{106}$. S'il fait appel à Patrick, c'est donc parce qu'il reconnaît la primauté de celui-ci et de la paruchia d'Armagh. Qui plus est, le monastère devait être le lieu de sa résurrection, c'est-à-dire l'endroit où il serait enterré et où se trouveraient ses reliques après sa mort. On a donc là un exemple de lieu saint consacré sans reliques mais dont on sait que des reliques y sont destinées un peu plus tard.

Un peu plus haut dans le même texte, Patrick délimite le lieu d'une église consacrée à Dieu, et qui lui est dédiée : "Saint Patrick délimita l'endroit pour lui-même avec sa crosse, et il fut le premier à y offrir le corps et le sang du Christ ${ }^{107}$. "L'église est fondée par un scribe, prêtre et ermite, Binén mac Lugu. Il est donc normal que Patrick la consacre en tant qu'évêque, comme l'indique le canon 23 du premier synode de Patrick, daté du vie siècle : "Si un prêtre a construit une église, il ne doit pas officier avant d'amener son propre évêque à la consacrer, car c'est ainsi que cela doit être ${ }^{108}$. " Par contre, il est intéressant de noter que l'église lui est dédiée de son vivant : c'est ce qui a fait penser que les Irlandais consacraient leurs églises à des saints vivants, raison pour laquelle ils n'auraient pas eu de reliques ${ }^{109}$. Mais il s'agit sans doute là aussi d'une reconnaissance de la primauté d'Armagh. Le terme employé pour la délimitation de l'endroit est le verbe latin signo, are, qui confirme et complète le sens du mot irlandais tórann : il signifie en effet aussi bien tracer un rempart, une limite donc, avec une charrue, que marquer d'un signe distinctif ${ }^{110}$. Or, les premières limites étaient tracées avec une charrue ${ }^{111}$, et c'est aussi avec une pointe que le terme irlandais

105. The Patrician texts in the Book of Armagh, éd. BIELER, Ludwig, Dublin, DIAS, 1979, p. 176, § 14/2 : Asbert Fiacc frisin aingel nand rigad con tísed Patricc do thoorund a luic lais 7 dia choisecrad, 7 combed húad nu ggabad a locc.

106. Seuls les évêques peuvent consacrer une église. Voir The Bishop's synod ("The first synod of st. Patrick »): a symposium with text, translation and commentary, éd. FARIS, M. J., Liverpool, F. Cairns, 1976.

107. The Patrician texts in the Book of Armagh, éd. BIELER, Ludwig, Dublin, DIAS, 1979, p. $172, \S 7,1.7-8$ : et sanctus Patricius signauit locum sibi suo baculo, et ipse primus corpus et sanguinem Christi obtulit.

108. The Bishop's synod ("The first synod of st. Patrick") : a symposium with text, translation and commentary, éd. FARIS, M. J., Liverpool, F. Cairns, 1976, p. 5, canon 23 : si quis presbiterorum aecclesiam aedificaverit, non offerat antequam adducat suum pontificem ut eam consecret, quia sic decet.

109. OLDEN, Thos., "On an early Irish tract in the Leabhar Breac describing the mode of consecrating a church ", Transactions of the St Paul's ecclesiastical society IV (1897), p. 99. 110. Le grand Gaffiot, dictionnaire latin-français, nouvelle éd. FlobERT, Pierre, Paris, Hachette, 2000, art. signo, are.

111. DumÉzIL, Georges, "Aedes rotunda Vestae ", Rituels indo-européens à Rome, Paris, Klincksieck, 1954, p. 30. VENDRYES, Joseph, "Le sillon et la frontière ", Mélanges publiés en l'honneur de M. Paul Boyer, Paris, Champion, 1925, p. 13-17. 
trace la limite, le terme tórann ayant pour origine rind, la " pointe ${ }^{112}$ ". Le signe distinctif, signum, était une borne, comprise dans les textes chrétiens irlandais comme une croix $^{113}$. Patrick utilise sa crosse (bacula, le terme latin) pour délimiter le lieu, ce qui permet de confirmer très tôt l'usage de la crosse dans le rite de consécration des églises en Irlande. Mais on ne sait pas si son utilisation est faite pour tracer la limite, tracer ou graver des croix. Il s'agit peut-être des deux, les croix pouvant être marquées aux points cardinaux lors du tracé de la limite. Il se peut même que Patrick utilise sa crosse pour tracer l'alphabet, qui pourrait en l'occurrence être le signe distinctif de la délimitation ${ }^{114}$. Enfin, ce passage sur Patrick est intéressant, car il indique qu'une messe est dite au moment de la consécration, chose que ne fait pas le traité irlandais sur la consécration des églises, peut-être parce qu'il manque la fin du texte. La messe est le premier acte, en date, de la consécration d'une église : jusqu'au $\mathrm{VI}^{\mathrm{e}}$ siècle, c'est la première célébration de la messe qui consacre l'église ${ }^{115}$.

La troisième partie du traité sur la consécration des églises est donc très ancienne, puisqu'on en trouve des mentions indirectes dès le vil ${ }^{\mathrm{e}}$ siècle. Cette cérémonie du tour de l'église, avec chant de psaumes, stations et gravures de croix sur les parois de l'église, prendrait la place d'une cérémonie encore plus ancienne, remontant au début de la christianisation de l'Irlande, le pèlerinage au tombeau du saint, marqué par des prières, des stations et des stèles en forme de croix. Le nombre de prières aurait diminué de quinze à douze, les stations se faisant autour de l'église aux quatre points cardinaux, et les croix gravées auraient remplacé les stèles. Cette partie aurait ainsi des racines aussi anciennes que la consécration des autels, qui constitue l'acte le plus ancien des rites de consécration de l'église, et elle aurait été intégrée dans le rituel de consécration des églises en lieu et place de la consécration des reliques. On peut aussi légitimement se demander si la cérémonie du tour de l'église, qu'on retrouve au début de l'ordo 40 du Pontifical romano-germanique et à la première place dans le rite ambrosien du manuscrit de Lucques, n'aurait pas une origine irlandaise, comme la coutume d'écrire l'alphabet sur le sol.

On retrouve la mention de circuit autour de l'église avec aspersion d'eau bénite et récitation de psaumes, joints avec le dépôt de reliques,

112. Lexique étymologique de l'irlandais ancien, éd. VENDRYES, Joseph, puis BACHELLERY, Edouard, LAMBERT, Pierre-Yves, Paris, CNRS, Dublin, DIAS, 1974, 1978, R-31-32; T-113-114. 113. WASSERSCHLEBEn, Heinrich, Die irische Kanonensammlung, Leipzig, B. Tauchnitz, 1885, Liber XLIV, cap. 3.

114. Sims-WilLIAMS, Patrick, "Byrtferth's ogam signature ", Britain and early Christian Europe : studies in early medieval history and culture, Aldershot, Variorum, 1995, XI, p. 283291. Patrick Sims-Williams suggère, p. 288 et note 40, que la délimitation du terrain pour une église pouvait être faite avec l'alphabet.

115. Le Liber Ordinum en usage dans l'Eglise wisigothique et mozarabe d'Espagne du V'au XI siècle, éd. FEROTIN, D. Marius, Paris, F. Didot, 1904, col. 507 ("Appendice III. La dédicace des églises chez les Wisigoths ", col. 506-515). IognA-Prat, Dominique, La Maison Dieu : une histoire monumentale de l'Eglise au Moyen Âge (v. 800-v. 1200), Paris, Seuil, 2006, p. 45-47. 
dans un texte souvent mentionné dans les études sur la dédicace des églises, la "Vie de saint Gall ", écrite par Wahlafrid vers 830-840. Celui-ci évoque la dédicace d'une église par saint Colomban. Le culte de celle-ci était retourné aux dieux païens et Colomban commence par jeter les idoles dans le lac, puis "Saint Colomban ordonna qu'on lui apportât de l'eau, et, l'ayant bénie, en aspergea le temple, et dédicaça l'église pendant que ceux qui psalmodiaient en faisaient le tour. Ensuite, invoquant le nom de Dieu, il oignit l'autel et y déposa les reliques de sainte Aurélie, et, ayant revêtu l'autel de nappes, ils accomplirent la messe selon la règle ${ }^{116}$ ". Le récit date de l'époque carolingienne, mais la description de la cérémonie est assez précise, et l'attribution à saint Colomban n'est sans doute pas due au hasard. L'essentiel de la cérémonie se retrouve dans le traité irlandais de consécration des églises : eau bénite, aspersion de l'église, circuit en psalmodiant, onction de l'autel qu'on revêt de nappes. Ces éléments se retrouvent aussi dans les rituels gallicans, y compris la récitation de psaumes en faisant le tour de l'église qu'on trouve dans l'ordo 41. Elle est mentionnée dans le texte Quid significent duodecim candelae, commentaire carolingien daté de 840 environ et qui donne l'explication d'un ordo de consécration proche de l'ordo du Pontifical romano-germanique ${ }^{117}$ : le texte mentionne l'évêque envoyant ses aides autour de la basilique en chantant des psaumes et en l'aspergeant pendant que lui-même se tient au milieu de l'église ${ }^{118}$. Ni Wahlafrid ni le commentaire carolingien écrit à la même époque que la vie de saint Gall ne précisent cependant quels psaumes sont chantés. On peut juste préciser que, dans ces textes, ce n'est pas l'évêque qui fait le circuit autour de l'église.

\section{Prise de possession de la terre et psaumes de malédiction}

La cérémonie que conduit Colomban correspond cependant aussi au rituel que prescrit Grégoire le Grand dans sa lettre à Mellitus, compagnon d'Augustin de Cantorbéry, pour consacrer les anciens temples païens d'Angleterre : "Les temples des idoles ne doivent pas être détruits dans ce pays, mais qu'on détruise plutôt les idoles qui s'y trouvent, que l'on bénisse de l'eau, qu'on en asperge ces temples, que l'on y construise des autels, qu'on

\footnotetext{
116. WAHLAFrid StRABo, "Vita beati Galli confessoris ", éd. KRUSCH, Bruno, Passiones Vitaeque sanctorum aevi merovingici, Hannovre, MGH, "Scriptorum rerum merovingicarum, T. IV ", 1902, T. II, p. 289 : Beatus Columbanus jussit aquam afferri, et, benedicens illam, aspersit ea templum, et dum circuirent psallentes dedicavit ecclesiam. Deinde invocato nomine Dei, unxit altare et beatae Aureliae reliquias in eo collacavit, vestitoque altari missas legitime compleverunt.

117. REPSHER, Brian, The rite of church dedication in the early medieval era, Lewiston (New York), E. Mellen Pr., 1998, p. 33-39, 67-107; trad. du texte p. 171-196. Édition du texte dans Le pontifical romano-germanique du $x^{e}$ siècle, éd. Vogel, Cyrille, Elze, Reinhard, Rome, Vatican, « Studi e Testi, 226 », 1963, p. 90-121.

118. REPSHER, Brian, The rite of church dedication in the early medieval era, Lewiston (New York), E. Mellen Pr., 1998, p. 181, § 32.
} 
y place des reliques ${ }^{119}$. " La mention de la destruction des idoles suivie d'aspersion d'eau bénite est à comparer avec le rituel décrit dans le traité irlandais, où des prières pour chasser et maudire les démons sont récitées juste après la consécration de l'eau bénite, et avant la prise de possession de l'église.

Les monastères des îles Britanniques étaient souvent construits sur le site d'anciens sanctuaires, ou à proximité, ce qui permet de comprendre pourquoi il fallait un rituel d'expulsion. On en trouve un exemple dans le récit d'Aethelwulf, De Abbatibus ${ }^{120}$, écrit au début du IX ${ }^{\mathrm{e}}$ siècle et relatant la vie de six abbés northumbriens. L'un deux, Eanmund, désirant fonder un monastère dépendant de Lindisfarne, envoya un de ses moines auprès d'Egbert, moine anglo-saxon installé en Irlande, puis abbé d'Iona à la fin de sa vie ${ }^{121}$, pour lui demander un autel et des conseils. Egbert est désigné comme évêque (pontifex) dans le texte, ce qui l'autorise à consacrer l'autel. Le moine revint avec un autel consacré par Egbert et dédié à saint Pierre ${ }^{122}$, et la description de l'endroit où s'installer, même s'il ne l'avait pas vu de ses propres yeux : les moines devaient construire l'église au sommet d'une colline, à l'endroit où des buissons d'épines devraient être arrachés par leurs soins. Eanmund et ses moines s'exécutent, et ils reçoivent à ce moment-là un autre message d'Egbert, se réjouissant de ce qu'ils aient chassé une "bande du diable " en arrachant les épines où ils logeaient.

Un autre exemple est donné par Bède ${ }^{123}$, qui relate la fondation, à la demande du roi Aethelwald, du monastère de Lastingham par Cedd, moine de Lindisfarne. Cedd choisit un lieu dans des montagnes escarpées et retirées, propices aux voleurs et aux bêtes sauvages. Là, " dans son zèle, l'homme de Dieu s'appliqua d'abord, par ses prières et ses jeûnes, à purifier de l'ancienne saleté de ses turpitudes le lieu qu'il avait reçu pour le monastère, et à y asseoir ainsi les fondations du monastère, puis il demanda au roi de lui concéder la faculté et le pouvoir d'y demeurer pour y prier tout le

119. BÈDE LE VÉNÉRABLE, Histoire ecclésiastique du peuple anglais, éd. LAPIDGE, Michael, trad. Monat, Pierre, Robin, Philippe, intr. et notes CRÉPIN, André, Paris, Le Cerf, "Sources Chrétiennes n 490 », 2005, T. I, Livre I, 30, 2, p. 248-249 : uidelicet quia fana idolorum destrui in eadem gente minima debeant, sed ipsa quae in eis sunt idola destruantur, aqua benedicta fiat, in eisdem fanis aspergatur, altaria construantur, reliquiae ponantur.

120. Aethelwulf, De Abbatibus, éd. CAMPBell, Alistair, Oxford, Clarendon Pr., 1967, p. 10-17, ch. 6. Cet exemple, ainsi que le suivant, et son interprétation, est donné par FARR, Carol Ann, Lection and interpretation : the liturgical and exegetical background of the illustrations in the Book of Kells, Austin, University of Texas, 1989 (thèse), p. 164-191 (plus particulièrement p. 164-177). Ce chapitre n'apparaît pas dans l'édition de sa thèse.

121. BĖDE LE VÉNÉRABLE, Histoire ecclésiastique du peuple anglais, éd. LAPIDGE, Michael, trad. Monat, Pierre, Robin, Philippe, intr. et notes CRÉPIn, André, Paris, Le Cerf, "Sources Chrétiennes n ${ }^{\circ} 490$ et 491 ", 2005, T. 2, Livre III, 27, p. 166-173 et T. 3, Livre V, 9, p. 50-57.

122. L'autel de Cuthbert est également dédié à saint Pierre.

123. BĖDE LE VÉNÉRABlE, Histoire ecclésiastique du peuple anglais éd. LAPIDGE, Michael, trad. Monat, Pierre, Robin, Philippe, intr. et notes CréPIN, André, Paris, Le Cerf, " Sources Chrétiennes n 490 ", 2005, T. 2, Livre III, 23, 1-2, p. 128-131. 
temps du carême qui approchait ${ }^{124}$ ". Puis il fonde le monastère et le dote d'institutions conformes au rite de Lindisfarne.

Ce sont donc deux exemples de fondation d'églises et de monastères selon des rites insulaires. Le choix du lieu, en hauteur sur une colline située à l'écart, est conforme à la fois à l'emplacement des sanctuaires païens et des monastères qui les ont remplacés ${ }^{125}$. La description de la fondation, la nécessité de purifier le lieu avant toute installation, justifie l'idée que les lieux de culte s'installaient à l'emplacement d'anciens sanctuaires. Le rituel d'exorcisme faisait partie intégrante de la consécration d'une église. L'histoire de Cedd, racontée par Bède, permet en outre de situer la cérémonie de consécration des églises au moment de Pâques, les préparatifs ayant lieu pendant le Carême, ce qui est cohérent avec la récitation des psaumes des montées, repris au rite du baptême et de la veillée de Pâques. L'enluminure du Livre de Kells, illustrant la Tentation du Christ (folio 202 v $^{\circ}$ ), et qui représente Jésus au sommet d'une église, peut ainsi s'expliquer : la lecture du texte de la tentation du Christ avait lieu au début du Carême, c'était aussi le moment où se préparait la consécration des églises, et où débutait la préparation des catéchumènes au baptême.

Les éléments contenus dans le traité irlandais de consécration des églises peuvent donc se classer en plusieurs parties plus ou moins distinctes : prise de possession du sol avec fabrication d'eau bénite, récitation de psaumes de malédiction et écriture de l'alphabet, consécration de l'autel, consécration de l'église avec récitation de psaumes graduels, aspersions d'eau bénite, gravures de croix et onctions. Toutes ces opérations remontent à une époque ancienne, au VI ${ }^{\mathrm{e}}$ ou au VII ${ }^{\mathrm{e}}$ siècle, mais elles ont des provenances diverses, et semblent avoir été juxtaposées de manière quelquefois hasardeuse. On les retrouve dans la liturgie gallicane, mêlées de quelques gestes orientaux, ou encore dans des textes hagiographiques, irlandais ou northumbriens, anciens; certaines sont spécifiques à l'Irlande, qu'elles en soient originaires et se soient répandues par la suite dans l'ensemble de l'Occident, comme l'écriture de l'alphabet, ou bien qu'on ne les trouve que dans les rites irlandais, comme l'utilisation de psaumes de malédiction ou comme l'ensemble de la troisième partie du traité, décrivant l'emploi des psaumes graduels, et qui prend la place de la consécration des reliques de la liturgie romaine.

124. BÈDE LE VÉNÉRABLE, Histoire ecclésiastique du peuple anglais, éd. LAPIDGE, Michael, trad. MonAt, Pierre, RoBIn, Philippe, intr. et notes CRÉPIN, André, Paris, Le Cerf, "Sources Chrétiennes n 490 ", 2005, T. 2, Livre III, 23, 2, p. 130, 1. 1-6 : studens autem uir Domini acceptum monasterii locum primo precibus ac ieiuniis a pristina flagitiorum sorde purgare, et sic in eo monasterii fundamenta iacere, postulauit a rege, ut sibi totum Quadragesimae tempus, quod instabat, facultatem ac licentiam ibidem orationis causa demorandi concederet. 125. O'Riain, Pádraig, "Pagan example and Christian practice : a reconsideration", Cultural identity and cultural integration : Ireland and Europe in the Early Middle Ages, éd. EDEL, Doris, Dublin, Four Courts Pr., 1995, p. 144-156. 
Il est ainsi possible, grâce à l'ordo irlandais et au schéma de dédicace du manuscrit d'Angers, de mettre au jour une chaîne intéressante, d'origine irlandaise, sur la consécration des églises. Celle-ci traduit une spatialisation du sacré, mise en scène dans une véritable liturgie de l'espace, matérialisée par l'inscription d'un double alphabet, la gravure de croix aux points cardinaux, et la récitation de psaumes graduels lors de la délimitation de l'église par circumambulation. Le lien établi avec un texte de la fin du VII ${ }^{\mathrm{e}}$ siècle (Liber Angeli de Tirechán) et avec le an turas (pèlerinage au tombeau du saint) encore antérieur ( $\mathrm{VI}^{\mathrm{e}}$ siècle au moins), transposé dans la troménie bretonne, permet d'affirmer l'origine irlandaise du rituel. Il confirme les relations étroites existant entre l'Irlande et la Bretagne armoricaine, et plus particulièrement avec l'abbaye de Landévennec.

\section{Annexe 1 - Dédicace des églises}

(Angers, Bibliothèque municipale 477 (461), folio $9 r^{\circ}$, cop. CNRS/IRHT, base Enluminures)

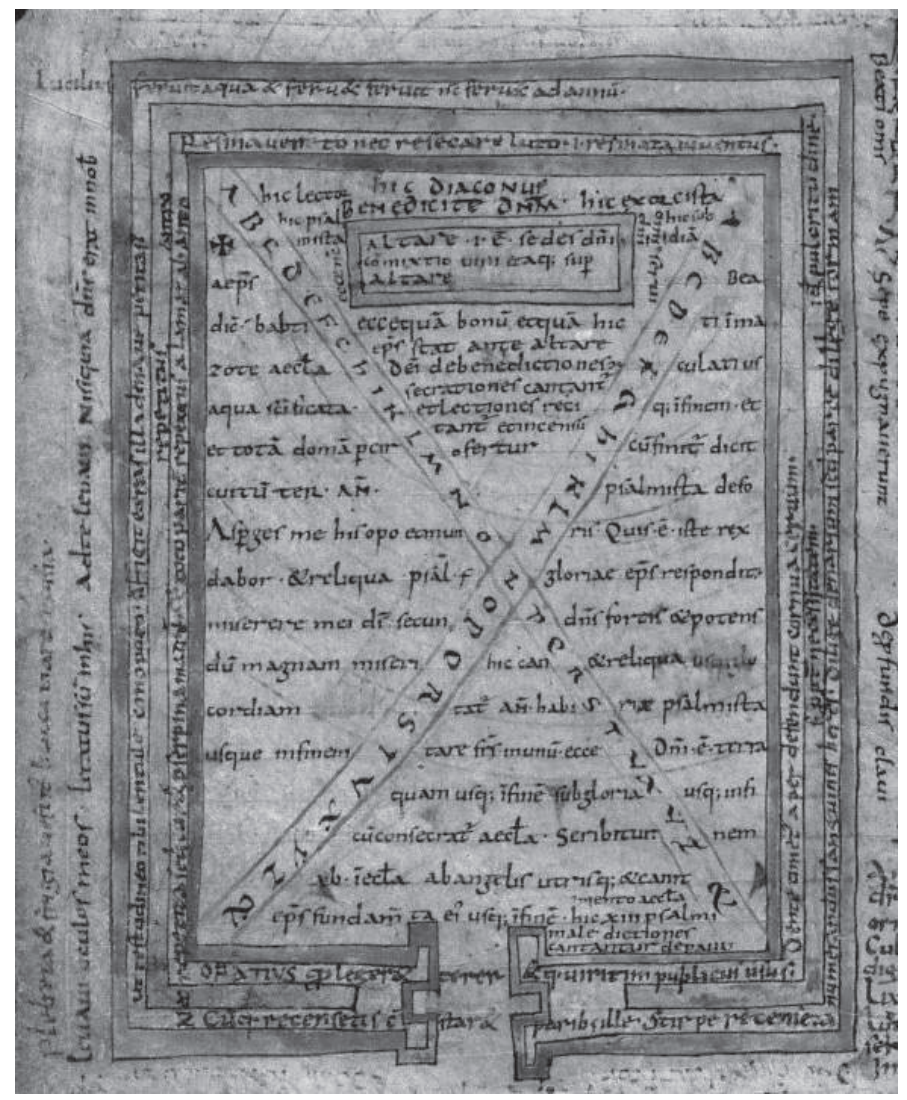




\section{Transcription du schéma de dédicace}

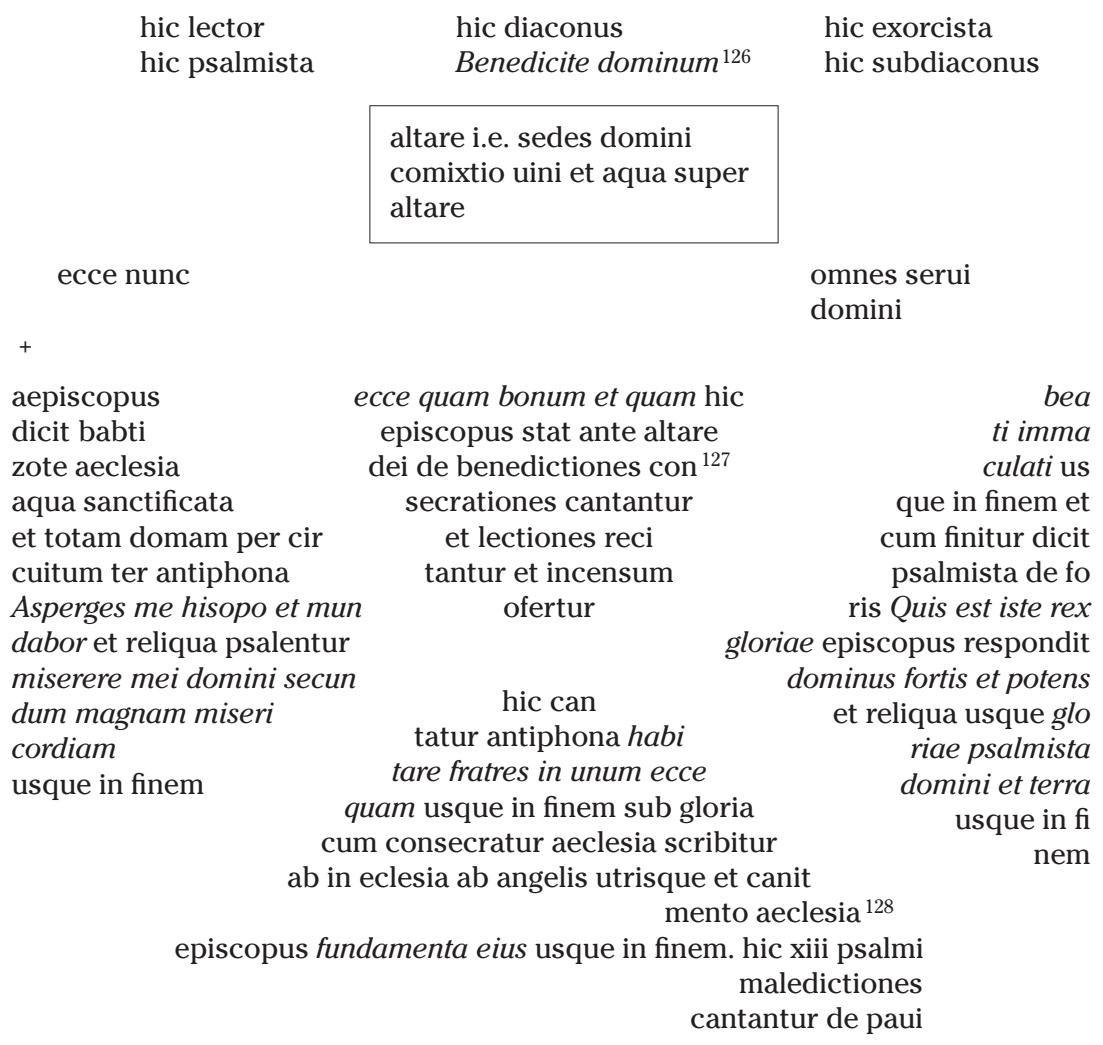

Côté gauche extérieur :

Ligne du haut : Plebeia et frygia uestitur bucca tiara enia (?) (Juvénal, Satires VI, v. 516, sauf le dernier mot. Trad. sous son menton plébéien, il a noué la tiare. L'orthographe du mot frygia au lieu de phrygia se trouve chez Servius Ad Verg. Aen. VII, 247).

126. Les italiques correspondent à des citations de psaumes, identifiés plus bas.

127. Con = o ouvert inversé, abréviation typique de l'écriture irlandaise. Voir BISCHOFf B., Paléographie, p. 96.

128. Hic xiii psalmi maledictiones cantantur de pauimento aeclesia(e) : retour sur la ligne que les scribes irlandais appellent cein fo eitte (" la tête sous l'aile "), pratique courante dans les manuscrits irlandais, mais aussi byzantins (remarque de Jean-Michel Picard que je remercie). Voir LAMBERT, Pierre-Yves, "Le vocabulaire du scribe irlandais ", Ireland and Northern France AD 600-850, éd. PICARD, Jean-Michel, Dublin, Four Courts Pr., 1991, p. 157-167. 
Ligne du bas : Leuaui oculos meos (ps. 120) ${ }^{129} /$ letatussum in his (ps. 121)/ ad te leuaui (ps. 122)/ nisi quia dominus erat in nobis (ps. 123).

Côté haut extérieur, gratté (effacé) : ps. 124-126

Côté droit extérieur :

Beati omnes (ps. 127)/ Sepe expugnauerunt (ps. 128)/ De profundis claui (ps. 129)

Côté bas extérieur, gratté (effacé) : ps. 130 (à droite de la porte) ; ps. 119 (à gauche de la porte : début du circuit).

Récapitulatif des psaumes : 12 psaumes graduels à l'extérieur (119 à 130); ps. 23, 8 quis est iste rex; ps. 23, 8 dominus fortis; ps. 50, 9 asperges me; ps. 50, 3 miserere mei; ps. 86 fundamenta eius; ps. 118 beati immaculati; ps. 132 habitare fratres in unum ecce quam; ps. 132 ecce quam bonum et quam; ps. 133 benedicite dominum ${ }^{130} ; 13$ psaumes de malédiction (non spécifiés).

Dans les murs :

En bas, ligne du haut : " oratius : quod legeret terretque uiritim publicus usus " (Horace, Lettres, Livre II, Lettre 1, v. 92). Ligne du bas : " cumque recensetis constaret partibus ille " (Prudence, Peristephanon XI, Ad Valerianum episcopum de passione Hippolyti beatissimi martyres, v. 147), suivi de "stirpe recenseta ", continué sur le côté droit, ligne du bas "numerandus sanguinis heres " (Prudence, Liber Apotheosis, v. 1000).

Côté droit, ligne du haut : "Dente timetur aper defendunt cornua ceruum » on craint le sanglier par sa dent, les cornes du cerf le défendent (Martial, Epigrammes, 13.94, cité par Isidore de Séville, Etymologies XII, 1, 22). Interlignes : « s. propter necessitatem ». Ligne du bas : " numerandus sanguinis heres" (Prudence), suivi de " dilige denarium sed parce dilege formam " (Caton, Distiques, Poet.Lat.minores III 4, 4, éd. Baehrens), et de " et pulchritudinem " (id.; utilisé par Sedulius Scottus, cf. Hellmann, p. 35, 1. 7).

En haut, ligne du haut : " Lucilius : feruit aqua et feruet : feruit nunc, feruet ad annum " (Lucilius, d'après Quintilien, Institution oratoire, Livre 1, ch. 6; utilisé par Priscien, Gramm. Lat. 2, 478, 18). Ligne du bas : "Resina, Veneto, nec resecare luto "faire tomber (les ongles) avec de la résine ou de l'argile de Venise (Martial, Epigrammes, Livre II, 74), suivi de ".i. resinata iuuentus ", des jeunes gens passés à la résine (Juvénal, Satires, VIII, v. 114).

Côté gauche, ligne du haut : "Ut testudineo tibi, Lentule, conepeo " sous le voile du berceau incrusté d'écailles ( Juvénal, Satires VI, v. 80, éd. Labriole, Belles Lettres, 1931, p. 62), suivi de : "Affigit ceras illa de naue petitas " avec de la cire prise sur le

129. Numérotation des psaumes selon la Vulgate de Jérôme (Psautier Gallican). Pour la numérotation dans l'édition actuelle du psautier, il faut rajouter 1.

130. Introit utilisé pour la messe de la dédicace de l'église Saint Michel construite à Rome sur la Via Salaria. Dédicace mentionnée dans quatre messes du sacramentaire léonien du début du VII ${ }^{\mathrm{e}}$ siècle. KARP, T., "The twilight of troping", Music in medieval Europe : studies in honour of Bryan Gillingham, éd. Gillingham, B., Balley, T., Santosuosso, A. C., Ashgate Publ., 2007, p. 79-94 (voir p. 84). 
navire (Juvénal, Satires IX, v. 149). Ligne du bas : « Nec repetita sequi curet proserpina matrem " (Virgile, Géorgiques I, 39), suivi de : " et toto pariter repetitus clamor ab antro " (Juvénal, Satires VI, v. 328).

\section{Annexe 2 - Comparatif des rituels de consécration des ordines et sacramentaires, établi d'après le rituel irlandais}

Non compris l'ordo 40 du Pontifical Romano-Germanique, qui reprend tous les éléments, de façon très amplifiée et dans un ordre différent.

\begin{tabular}{|c|c|c|}
\hline & Date du manuscrit & Date du texte \\
\hline Traité irlandais & $\mathrm{XV}^{\mathrm{e}}$ siècle & $\mathrm{X}^{\mathrm{e}}-\mathrm{XI}{ }^{\mathrm{e}}$ siècles \\
\hline Ms 477 Angers & fin IXe siècle & fin $\mathrm{IX}^{\mathrm{e}}-\mathrm{X}^{\mathrm{e}}$ siècle \\
\hline Sacramentaire Gélasien/ Missale Francorum & VIII ${ }^{\mathrm{e}}$ siècle & $\mathrm{VII}^{\mathrm{e}}$-VIII ${ }^{\mathrm{e}}$ siècle \\
\hline Sacramentaire de Gellone & VIII ${ }^{\mathrm{e}}$ siècle & \\
\hline Sacramentaire d'Angoulême & VIII ${ }^{\mathrm{e}}$ siècle & \\
\hline Ordo 41 & IXe- $\mathrm{X}^{\mathrm{e}}$ siècle & ca. $750-775$ \\
\hline Euchologe Barberini & $\mathrm{VIII}^{\mathrm{e}}$ siècle & $\mathrm{VIII}^{\mathrm{e}}$ siècle \\
\hline Lucques & $\mathrm{XI}^{\mathrm{e}}$ siècle & $?$ \\
\hline
\end{tabular}

\section{Traité irlandais}

1) Sol : entrée de l'évêque; consécration eau et sel; psaumes et prières pour chasser les démons; psaumes et prières pour maudire les démons; prières de consécration du sol; inscription de l'alphabet, SE- NW, les O se croisent.

2) Autel : mélange hostie, vin et eau; inscription + aux angles et $3+$ au milieu; lavement table et pied de l'autel; encens; consécration linge, patène, calice.

3) Église : évêque et 2 prêtres à l'extérieur/ 3 prêtres à l'intérieur; évêque grave + est; chant 3 psaumes graduels par point cardinal (à partir de l'est ou de l'ouest); ps. 23 pour entrer; même entrée qu'en 1.

4) Murs - aspersion intérieure : diacre apporte eau et sel au SE; évêque grave + SE et asperge; 3 prêtres aspergent côté, toit, fontaine; ps. 50 ; même chose à chaque point cardinal.

5) Murs - aspersion extérieure : même chose à l'extérieur.

\section{Ms 477 Angers}

1) Sol : entrée, ps. 133 ; ps. 132; inscription de l'alphabet à partir de l'angle gauche à l'est, les $\mathrm{O}$ se croisent; ps. 86; 13 psaumes de malédiction.

2) Autel : mélange eau, vin; bénédictions; lectures; encens.

3) Eglise : 12 psaumes graduels à l'extérieur, à partir de l'ouest; ps. 118; ps. 23 pour entrer.

4) Murs - aspersion intérieure : + gravée au NE; évêque baptise l'église avec eau sanctifiée; circuit 3 fois; ps. 50.

5) Murs - aspersion extérieure. 


\section{Sacramentaire Gélasien/Missale Francorum}

1) Sol.

2) Autel : mélange eau, vin; inscription + aux angles; lavement table et pied; encens; consécration linge, patène, calice.

3) Église.

4) Murs - aspersion intérieure.

5) Murs - aspersion extérieure.

\section{Sacramentaire de Gellone}

1) Sol : bénédiction eau, sel, eau et sel; exorcismes eau, sel, eau et sel.

2) Autel : mélange eau, vin; inscription + aux angles; lavement table et pied; encens; consécration linge, patène, calice.
3) Église.
4) Murs - aspersion intérieure.
5) Murs - aspersion extérieure.

\section{Sacramentaire d'Angoulême}

1) Sol : entrée; litanie; mélange eau, vin; aspersion de l'église; bénédiction de l'église.

2) Autel : litanie; aspersion autel; bénédiction; onction, inscription + aux angles et au centre; onction église; bénédiction vases.

3) Église : translation des reliques; déposition des reliques.

4) Murs - aspersion intérieure.

5) Murs - aspersion extérieure.

\section{Ordo 41 :}

1) Sol : illumination 12 chandelles; entrée de l'évêque, ps. 23; litanie, prières; inscription de l'alphabet, de l'angle gauche à l'est; mélange sel, eau, cendre; exorcisme. 2) Autel : mélange eau, vin; inscription + aux angles; aspersion autel et murs, ps. 50; onction + centre et angles de l'autel et murs; bénédiction linge, vases ornements.

3) Église : translation et déposition des reliques; habillage de l'autel.

4) Murs - aspersion intérieure : aspersion des murs intérieurs; 2 ou 3 prêtres à l'extérieur; aspersion du sol; eau au pied de l'autel; encens; onction des 5 + de l'autel; onction du sol, ps. 86; onction des murs.

5) Murs - aspersion extérieure.

\section{Euchologe Barberini}

1) Sol.

2) Autel : eau bénite; aspersion autel, ps. 50; essuie autel, ps. 131; onction autel, $3+$; inscription + sur les colonnes de l'autel, ps. 132; nappe, ps. 92; encens, ps. 25 .

3) Église : translation des reliques; ps. 23 pour entrer; déposition des reliques.

4) Murs - aspersion intérieure.

5) Murs - aspersion extérieure. 


\section{Lucques}

1) Sol.

2) Autel.

3) Église : archevêque dehors; ps. 50, aspersion église à l'extérieur; inscription + avec crosse sur porte, alphabet sur murs; onction $3+$ sur chaque mur, 3 chandelles, ps. 50 et 66 ; tape à la porte, ps. 23 pour entrer.

4) Murs - aspersion intérieure : entrée, ps. 99; aspersion église, ps. 50 ; inscription alphabet sur cendre, ps. 118; onction 3 + sur les murs; illumination 12 chandelles.

5) Murs - aspersion extérieure : (avant l'entrée).

\section{RÉSUMÉ}

L'étude du seul traité irlandais sur la consécration des églises ( $\mathrm{xI}^{\mathrm{e}}$ siècle) et sa comparaison avec les sacramentaires et ordines du viII ${ }^{\mathrm{e}}$ siècle permettent de relever des analogies avec la liturgie gallicane, mêlée de quelques éléments orientaux. La découverte d'un schéma de dédicace dans le ms 477 d'Angers ( $\mathrm{IX}^{\mathrm{e}}$ siècle), d'origine bretonne (Landévennec) et d'influence irlandaise, confirme quant à elle les singularités du rituel irlandais : inscription d'un double alphabet latin sur le sol ; utilisation de psaumes de malédiction; circumambulation de l'église en récitant des psaumes graduels. Les textes hagiographiques du $\mathrm{vII}^{\mathrm{e}}$ siècle complètent la compréhension du rituel irlandais : alors que l'installation des monastères sur le lieu d'anciens sanctuaires explique l'utilisation des psaumes de malédiction, celle des psaumes graduels remonte à la coutume du pèlerinage au tombeau du saint, lequel fait le tour du domaine monastique (an turas irlandais, troménie bretonne). La cérémonie décrit ainsi une spatialisation du sacré et confirme les liens religieux entre la Bretagne et l'Irlande au Moyen Âge.

\section{ABSTRACT}

The study of the one Irish tract on the consecration of churches (11 th century) and the comparison of it with the sacramentaries and ordines of the $8^{\text {th }}$ century allow us to identify analogies with the Gallican liturgy, mixed with some oriental details. The discovery of a dedication scheme contained in the $9^{\text {th }}$ century Angers manuscript (ms 477), which has a Breton origin (Landévennec) and shows Irish influences, confirms the peculiarities of the Irish rite: the writing of a double Latin alphabet on the ground; the use of cursing psalms; the circumambulation of the church while reciting gradual psalms. The hagiographical literature of the $7^{\text {th }}$ century completes the comprehension of the Irish rite, while the foundation of monasteries on the location of ancient sanctuaries explains the use of cursing psalms; that of the gradual psalms goes back to the custom of pilgrimages to the grave of the saint, which go round the monastic domain (Irish an turas, Breton troménie). The ceremony thus describes a spatializing of the sacred and confirms the religious links between Brittany and Ireland in the Middle Ages. 